\title{
Buoyancy-Generating Agents for Stomach-Specific Drug Delivery: An Overview with Special Emphasis on Floating Behavior
}

\author{
Rania A. H. Ishak
}

Department of Pharmaceutics and Industrial Pharmacy, Faculty of Pharmacy, Ain Shams University, Monazamet El Wehda El Afrikeya street, Abbassiah, Cairo, Egypt.

Received, November 19, 2014; Revised, February 18, 2015; Accepted, March 5, 2015; Published, March 6, 2015.

\begin{abstract}
Gastric retentive drug delivery provides a promising technology exhibiting an extended gastric residence and a drug release independent of patient related variables. It is usually useful in improving local gastric treatment as well as overcoming drug-related problems .i.e. drugs having narrow absorption window, short half-life or low intestinal solubility. Buoyancy is considered one of the most promising approaches for gastro-retention of dosage forms. Floating drug delivery systems have a bulk density lower than gastric fluids and thus remain buoyant in the stomach causing an increase in gastric residence time. The buoyancy of these systems is attained by the aid of substances responsible to generate the low density. Various agents with different mechanisms were adopted either gas-generating agents, air entrapping swellable polymers, inherent low density substances, porous excipients, hollow/porous particles inducing preparation techniques or sublimating agents. Therefore, this review gives an exclusive descriptive classification of the different categories of these buoyancy-generating agents while representing the related research works. An overview is also conducted to describe relevant techniques assessing the floating behavior of such dosage forms either in vitro or in vivo. Finally, a collection representing FDA-approved floating pharmaceutical products is adopted with emphasis on the buoyancy-generating agent type used in each product.
\end{abstract}

This article is open to POST-PUBLICATION REVIEW. Registered readers (see "For Readers") may comment by clicking on ABSTRACT on the issue's contents page.

\section{INTRODUCTION}

The stomach is the most proximal organ of the gastro-intestinal (GI) tract (GIT) after the oesophagus. It has several functions; temporary storage of food input, mechanical breakdown of food into smaller particles; chemical digestion with breakdown of proteins and regulation of output of chyme into the duodenum (1).

Gastric emptying results from the net effects of propulsive forces within the stomach and the resistance to flow offered by the pyloric sphincter (2). Under fasting conditions, the GI motility is associated with some cyclic contractile events known as migrating myoelectric complex (MMC) that occurs every 1.5 to $2 \mathrm{~h}$. Therefore; the gastric residence time (GRT) of any undigested material can be expected to be short. However, in the fed state, the cycle MMC is disrupted and delayed causing a prolongation in GRT (3).

After ingestion, liquids are rapidly distributed throughout the entire stomach. They empty from the stomach according to first-order kinetics; i.e., proportional to the volume present in the stomach. The gastric emptying rate of solids shows a biphasic pattern: a lag phase during which little emptying occurs, followed by a linear emptying phase during which solid particles empty from the stomach by mainly zero-order kinetics, that is, independent of gastric volume $(2,4)$. The stomach empties solids completely over approximately 3 to $4 \mathrm{~h} \mathrm{(5).} \mathrm{Therefore} \mathrm{the} \mathrm{speed} \mathrm{of} \mathrm{emptying}$ liquids, or contents consisting of smaller particles, is faster than that of solids.

The chemical composition of the chyme entering the duodenum also affects the rate of gastric emptying. If the chyme is too acidic, fatty or proteinaeous, gastric emptying is delayed (1).

Gastric retentive drug delivery (GRDD) provides a promising technology exhibiting an extended GI residence and a drug release independent of patient related variables (6). It is usually useful in overcoming drug-related problems i.e. drugs having narrow absorption window, short half-life or low intestinal solubility (7). Moreover, this delivery type has the tendency to maximize drug concentrations within gastric mucosa for better local treatment.

\footnotetext{
Corresponding Author - Rania A. H. Ishak; Faculty of Pharmacy, Ain Shams University, Monazamet El Wehda El Afrikeya street, Abbassiah, Cairo, Egypt. raniaaziz@pharma.asu.edu.eg
} 
There are three main gastro-retention approaches (7): mucoadhesion, where the dosage form adheres to the stomach walls (8-10); expansion, where the dosage form becomes too large to pass through the pyloric sphincter $(11,12)$; and floatation, where the dosage form floats on the stomach contents due to its low density (13-17).

However, the mucoadhesive drug delivery systems suffer from inconsistent and unpredictable gastric transit time due to continuous mucus turnover (18), in addition to the inherent risk of esophageal adherence resulting in drug-induced injuries (19). On the other hand, the gastro-retention of expandable dosage forms is enhanced by the combination of its substantial dimensions with the high rigidity to withstand the peristalsis and mechanical contractility of the stomach. These systems are sometimes referred to plug type systems because they may clog the pyloric sphincter preventing the exit of stomach contents (20).

Floating drug delivery systems (FDDS) have a bulk density lower than that of gastric fluids ( $\rho$ $\approx 1 \mathrm{~g} / \mathrm{cm}^{3}$ ) and thus remain buoyant in the stomach without affecting the gastric emptying rate for a prolonged period of time causing an increase in GRT (6). The buoyancy of these dosage forms is obtained by the inclusion of substances or agents responsible to generate the system low density. Therefore, this review gives an exclusive detailed description of the different types of these buoyancy-generating agents with presenting the related formulation approaches. Moreover, a report is conducted to illuminate different techniques studying the floating behavior of such buoyant dosage forms either in vitro or in vivo. An overview is also presented summarizing the buoyancy-generating agents in FDA-approved products that rely on floatation.

\section{METHODS USED TO ASSESS THE FLOATING BEHAVIOR OF GASTRO- RETENTIVE DOSAGE FORMS IN VITRO}

\section{For monolithic dosage forms \\ Buoyancy study}

The floating property of the monolithic systems is determined by visual observation. The floating lag time (FLT) and the total floating time are determined in the USP dissolution apparatus or in a beaker containing simulated gastric fluid SGF ( $\mathrm{pH} 1.2$, maintained at $37 \pm 0.5^{\circ} \mathrm{C}$ ). The time required for the tablet to rise to the surface of the medium and float is considered as FLT. The duration of time the dosage form remained constantly on the surface of medium is considered as the total floating time $(21,22)$.

Alternating Current Biosusceptometry (ACB) is a magnetically novel method used to characterize FLT and the tablet hydration rate. It is composed of an automated ACB sensor used to acquire magnetic images of floating tablets containing ferrite as a magnetic marker (23).

\section{Determination of the floating strength}

The floating strength of developed systems is an important parameter to be measured. As the presence of food in the stomach might increase the viscosity heavily, higher floating forces is needed to increase the probability of the tablet to remain afloat, reducing food effects on tablet retention (24). The floating strength of monolithic systems is determined in vitro by monitoring the total vertical force $F$ working on an immersed object, an experimental setup using an apparatus and methodology based on Timmermanns and Moës (Fig. 1) $(15$, 25-27). As the force $F$ determines the resultant weight of the floating tablet, it may be used to quantify and thus to further characterize floating behavior. The magnitude and direction of force $F$ and thus the resultant weight of the floating object is determined by the vectorial sum of the gravity $\left(\mathrm{F}_{\text {grav }}\right)$ and buoyancy $\left(\mathrm{F}_{\text {buoy }}\right)$ forces acting on the tablet as presented in Eq. 1.

$$
\begin{gathered}
\mathrm{F}=\mathrm{F}_{\text {buoy }}-\mathrm{F}_{\text {grav }} \\
=\mathrm{d}_{\mathrm{f}} \mathrm{gV}-\mathrm{d}_{\mathrm{s}} \mathrm{gV}=\left(\mathrm{d}_{\mathrm{f}}-\mathrm{d}_{\mathrm{s}}\right) \mathrm{gV} \\
\left.=\left(\mathrm{d}_{\mathrm{f}}-\mathrm{m} / \mathrm{V}\right) \mathrm{gV} \quad \text { (Eq. } 1\right)
\end{gathered}
$$

where $F$ is the total vertical force, $g$ is the acceleration of gravity, $d_{\mathrm{f}}$ is the density of the fluid, $d_{\mathrm{s}}$ is the density of the tablet, $m$ is the tablet mass and $V$ is the tablet volume.

The instrument (Fig. 1) used to determine the floating strength of the tablet samples measures the force equivalent to $F$ required to maintain the tablet totally submerged into the dissolution medium (15). According to Fig. 1, a test object (2) holder (either needle-like or mesh-like) (6) is connected to a metal base placed on an analytical balance (5) via a linear force transmitter (1) having a double role in maintaining the sample in the medium (3) and in transmitting the reaction force $F$ of either upward or downward direction (4) to the balance (15). For the performance of floating strength experiments the tablets are placed in a beaker with SGF $0.1 \mathrm{~N} \mathrm{HCl}$, so that the sample holding device is covered with 
dissolution medium. After the positioning of the tablet in the dissolution medium and subsequent taring of the analytical balance the sample is shifted under the sample holder. The floating strength is then determined as the weight diminution on the analytical balance over time (24).

\section{Determination of dosage form density and porosity}

For calculating the apparent densities of the tablets, their volumes and masses are determined. The height and diameter of the prepared tablets are measured using a micrometer and then used for the calculation of the volume of the cylindrical devices (28). The true density of the matrix devices is determined using a helium pycnometer $(28,29)$

The porosity $\varepsilon$ of the samples is then calculated using Eq. 2:

$$
\varepsilon=1-\left(\rho_{\mathrm{a}} / \rho_{\mathrm{t}}\right)
$$

where $\rho$ a represents the apparent density and $\rho t$ the true density of the dosage forms (28).

According to Sauzet et al. (29), the apparent density of the tablets $\rho$ a is also determined using the apparatus according to Timmermanns and Moës $(15,25-27)$, based on an immersed beam measuring the buoyancy force. The apparatus is made of a transparent parallelepipedic box filled with a liquid with a known density, which is SGF $0.1 \mathrm{~N} \mathrm{HCl} \mathrm{pH} \mathrm{1.2.} \mathrm{A} \mathrm{thin} \mathrm{flexible} \mathrm{polymethyl}$ methacrylate (PMMA) beam is immersed in the bath and is equipped with a sample holder made with metal wires (Fig. 2) at its free extremity while the other extremity is held firmly (29).

When the solid dosage is placed into the sample holder, it is vertically displaced by the buoyancy force and reaches a new steady state once the beam oscillations vanish. Measurement of the induced deviation in two dimensions allows the calculation of its density according to the Eq. (4) obtained by combination of the previous Eq. (1) and the following Eq. (3) (29).

The determination of displacement induced by the tablet is given by:

$$
\delta_{\mathrm{c}}=4\left(\mathrm{~L}^{3} / \mathrm{Ewh}^{3}\right) \mathrm{F}
$$

where $F$ is the force acting on the free extremity of the beam combining eq. (1) and (3) gives a direct expression for the tablet apparent density:

$$
\rho \mathrm{a}=\rho_{\mathrm{f}} /\left(1-\mathrm{Ewh}^{3} \delta_{\mathrm{c}} / 4 \mathrm{gL}^{3} \mathrm{~m}_{\mathrm{c}}\right) \quad \text { (Eq. 4) }
$$

where $\rho_{\mathrm{f}}$ is the liquid density, $\mathrm{m}_{\mathrm{c}}$ is the tablet weight, $\delta_{c}$ is the displacement of the beam and $\mathrm{E}$ is the elastic modulus of beam material (Young's modulus). The beam displacement $\delta_{\mathrm{c}}$ is measured by comparing two digital photographs captured with a webcam before and after the tablet insertion into the sample holder. The Image software allowed superposing the two images, to calibrate the images and to compute the displacement (Fig. 2). A millimetre scale was placed on the back wall of the tank for image calibration. A standard mass with a known volume was used as internal standard (29).

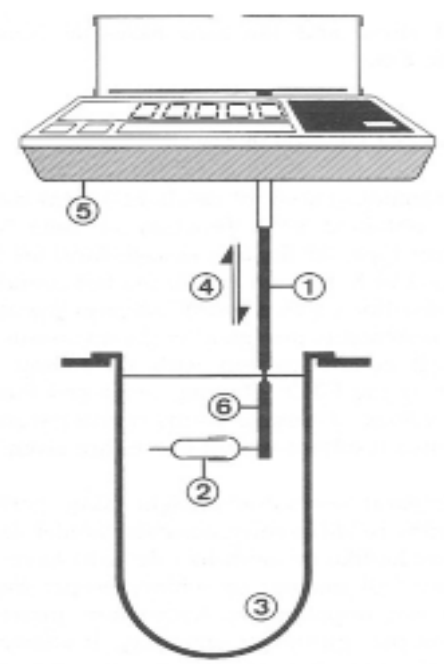

Figure. 1: Partial Schematic View of the ResultantWeight Measuring System. Reproduced from ref 15 with permission (15).

\section{Determination of the swelling index}

The swelling index is often calculated in order to find out the swelling ability of the monolithic systems (tablets, capsules) based on swellable hydrophilic polymers. These polymers, upon swelling, entrap air that lowers dosage form density. For calculating the swelling index, the previously weighed dosage forms are placed in a beaker containing SGF, are removed at different time intervals and then re-weighed. The swelling index can be measured by studying its dimensional changes, weight gain, or water uptake (30). Hence swelling index is calculated by the following formula:

$$
\text { Swelling index }=\left(W_{t}-W_{o}\right) / W_{o} \times 100
$$


where $W_{t}$ is the final weight of dosage forms at time " $t$ " and $W_{o}$ is the initial weight of dosage forms (30).

Benchtop Magnetic Resonance Imaging (MRI) is also used to monitor tablet hydration and swelling characteristics of tablet samples as well as carbon dioxide $\left(\mathrm{CO}_{2}\right)$ development inside the polymer shell (24). Tablets are placed in USP dissolution apparatus with SGF $0.1 \mathrm{~N} \mathrm{HCl}$ and removed for MRI measurements after predefined time intervals. Dark areas in the images are related to dry parts of the tablet or $\mathrm{CO}_{2}$ development inside the tablet core. Brighter areas of the tablets lead to follow hydration characteristics of the developed systems (24).

\section{For multiple-unit dosage forms}

Determination of FLT and buoyancy percentage

Floating properties of the multi-unit dosage forms are studied at $37 \pm 0.5^{\circ} \mathrm{C}$. A weighed amount or a specific number of the particles are soaked in a test solution either water or simulated gastric fluid (SGF, pH 1.2) with or without surfactant under stirring conditions at 50 or $100 \mathrm{rpm}$. The time taken by particles to float on the surface is determined (lag time). The percentage of floating or sinking particles is measured by visual observation (31).

On the other hand, an alternative technique is applied to measure the percentage of buoyancy. After the desired time, the layer of buoyant particles is pipetted and separated by filtration. Particles in the sinking particulate layer are also separated by filtration. Particles of both types are dried in a desiccator until constant weight. Both particle fractions are weighed and buoyancy is determined (Eq. 6) by the weight ratio of floating particles to the sum of floating and sinking particles (32-35).

$$
\text { Buoyancy }(\%)=\mathrm{W}_{\mathrm{f}} /\left(\mathrm{W}_{\mathrm{f}}+\mathrm{W}_{\mathrm{s}}\right) \times 100 \quad \text { (Eq. 6) }
$$

where $\mathrm{W}_{\mathrm{f}}$ and $\mathrm{W}_{\mathrm{s}}$ are the weights of the floating and settled particles, respectively.

\section{Determination of particle density and porosity}

The apparent particle density is determined by the projective image count method (36). Particles are placed on a glass plate. Heywood diameter and particle number are measured by an Image Processing and Analysis System. Subsequently, the apparent particle density is calculated according to Eq. (7).

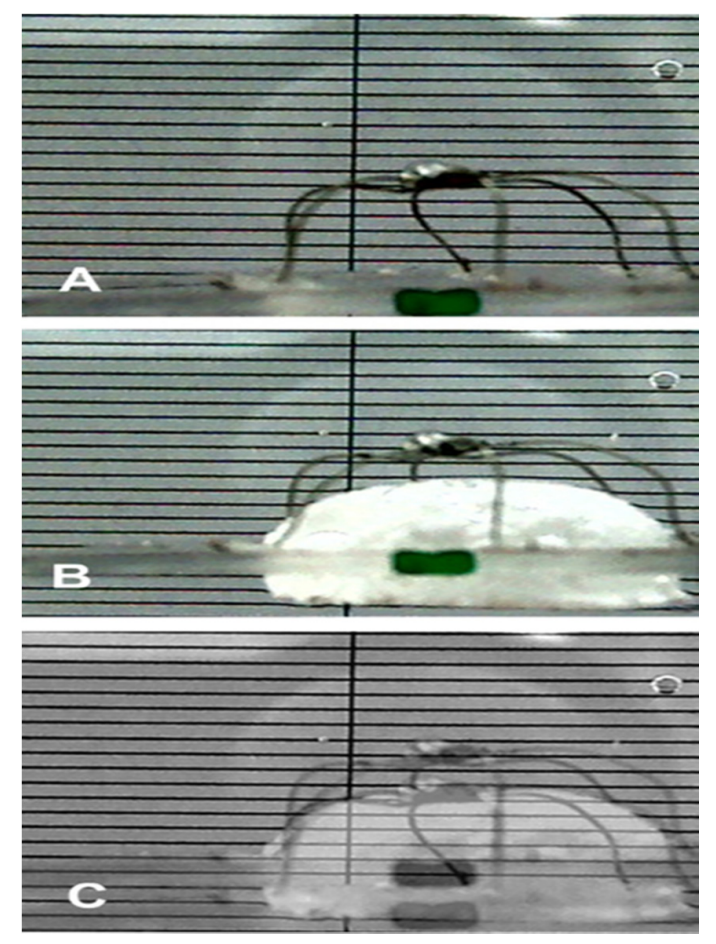

Figure. 2: Experimental Setup for the Determination of the Apparent Density A: image of the beam extremity with the sample holder. B: Due to the buoyant force of the tablet, the beam is lifted vertically. C: Difference between photographs A and B showing the displacement $\delta \mathrm{c}$. The millimetre scale is seen in the back. Reproduced from ref 29 with permission (29). 
Apparent particle density $=\mathrm{W} / \mathrm{V}$

$$
\left.=\mathrm{W} / \Sigma\left(\pi \cdot \mathrm{d}^{3} . \mathrm{n} / 6\right) \quad \text { (Eq. } 7\right)
$$

where $\mathrm{W}$, particles weight; V, particles volume; $\mathrm{d}$, Heywood diameter; and n, number of particles. The true density and porosity of multiple-unit dosage forms are assessed using mercury porosimetry (37). The mercury intrusion data are recorded and plotted against pressure. The porosity of particles is then calculated according to Eq. (8).

Particles Porosity $(\%)=\left(1-\rho_{\mathrm{a}} / \rho_{\mathrm{t}}\right)$ X 100 (Eq. 8)

$\rho_{\mathrm{a}}$, apparent density of particles; and $\rho_{\mathrm{t}}$, true density of particles (37).

\section{METHODS USED TO ASSESS THE GASTRO-RETENTION OF DOSAGE FORMS IN VIVO}

\section{X-ray radiography}

The buoyancy behavior of either monolithic or multiple-unit systems is assayed in vivo by administering floating and non-FDDS, loaded with barium sulfate $\left(\mathrm{BaSO}_{4}\right)$ as radiopaque agent, to human volunteers, beagle/mongrel dogs or albino rabbits. The study is conducted under fed and fasting conditions. The location of either dosage form is then monitored in the gastric region at determined time intervals using X-ray apparatus. Both floating time and GRT of the systems are then noticed and recorded $(14,30,38$ 48).

\section{Gamma ( $($ )-scintigraphy:}

Dosage forms radiolabelled with ${ }^{99 \mathrm{~m}} \mathrm{Tc}$ or ${ }^{111} \mathrm{In}$ are first prepared. The labeling efficiency of the process is determined by determining the radioactive counts using ascending ITLC plates. The $\gamma$-scintigraphy as a non-invasive technique is employed to measure the gastric transit rate with gamma camera. Gastric images of human volunteers or experimental animals using collimator are collected for about 1000 counts per second. The gamma scintigraphic imaging is started just after dosing and is carried out at specified time intervals under the dynamic planer conditions (49-62).

\section{Indirect methods}

\section{Pharmacokinetics study}

The bioavailability of some drugs as ofloxacin (63) and ciprofloxacin $\mathrm{HCl}$ (64) is strongly dependent on the local physiology in the GI tract and preferably is absorbed in the higher sections of the intestine. These drugs are readily soluble in the acidic environment of the stomach. In the intestine, where neutral to slightly alkaline $\mathrm{pH}$ conditions prevail; however, precipitation of the active compounds occurs, which adversely affects absorption in the lower sections of the intestine. Other drugs like furosemide (65), riboflavin (59, 66), ranitidine $\mathrm{HCl}$ (67), dipyridamole (68), famotidine $\mathrm{HCl}$ (69), norfloxacin (70), verapamil (71), repaglinide (61) and levodopa (62) suffer from poor bioavailability due to the presence of a narrow absorption window in the upper GIT. Therefore, the design and development of GRDDS for such drugs is beneficial. Pharmacokinetics study is performed from blood sampling estimating $C_{\max }, t_{\max }$ and AUC from the observed mean drug plasma concentration against time profile. $K_{\mathrm{el}}$ and $t_{1 / 2}$ are also computed. The extent of absorption from the prepared test formulation relative to the marketed or nonfloating one is calculated as the relative bioavailability. Also, drug concentrations could be determined in urine samples at scheduled time intervals following administration. Subsequently, cumulative amount of excreted drug in urine as a function of time is measured (66).

\section{Microbiological assay}

$H$. pylori causing peptic ulcer resides mainly in the gastric mucosa or at the interface between the mucous layer and the epithelial cells of the antral region of the stomach (72). Most antibacterial agents as amoxicillin (73), metronidazole (74), clarithromycin (75) and acetohydroxamic acid (76) have low minimum inhibitory concentrations (MIC) against $H$. pylori in culture due to the low concentration of the antibiotic reaching the bacteria under the mucosa, instability of the drug in the low $\mathrm{pH}$ of gastric fluid and short residence time of the antibiotic in the stomach (77). To improve the efficacy in eradicating the infection is to deliver the antibiotic locally in the stomach through FDDS (77, 78). Longer residence time will allow more of the antibiotic to penetrate through the gastric mucus layer to act on $\mathrm{H}$. pylori (79). The efficacy of antibiotic-containing floating delivery system to eradicate $H$. pylori is assessed by microbiological assay. Animals are inoculated with $H$. pylori culture broth containing known bacterial colony forming unit (CFU) via intra-gastric gavage. Fourteen days after infection, the drug was orally administered at different doses in the form of either floating or suspension. Placebo FDDS, used as a control, are 
administered in the same manner. One day after administration of the dose, the animals are killed and the stomachs are removed. Each stomach is homogenized and then plated on modified Skirrow's medium. The viable cell counts for each stomach are calculated by counting the number of colonies on the agar plates. The colonies are identified as $H$. pylori by morphology and urease activity. The number of colonies per plate is counted and expressed as log CFU per gastric wall (73-76).

\section{Determination of the pharmacological effect}

The gastro-protective effect of anti-ulcer agents as DA-6034, a new flavonoid derivative (80) or nizatidine (81), formulated in FDFs, are evaluated in experimental animals with gastric ulcers. The ulcers are induced either with biopsy forceps (80) or ethanol (81). Floating or control systems are orally administered for several days. The ulcer healing effects are evaluated using a gastric endoscope for several days after administration. Ulcer healing effects are estimated by grade ulcers from 0 to 5 , where ' 0 ' indicated a normal gastric wall, ' 1 ' a scar with similar to normal gastric wall, '2' insignificant erosion with flare, ' 3 ' severe erosion with flare and swelling, ' 4 ' a gastric ulcer with a blood spot, and grade ' 5 ' a bleeding gastric ulcer (80). Additionally, the ulcer protection index could be compared to control group (81).

\section{Pharmacodynamic study}

Metformin $\mathrm{HCl}$ is a glucose lowering agent with narrow absorption window. The effectiveness of the antidiabetic drug containing floating formulations was evaluated in vivo by measuring its hypoglycemic response in both normal and diabetic albino rats (82).

The in vivo antiulcer property of famotidine in FDDS was investigated using pyloric ligation method. The mean volume of gastric secretion, mean $\mathrm{pH}$ and mean total acid for formulation and control treated rat groups were calculated (83).

\section{Anti-tumor Activity}

The anticancer drug, 5-fluorouracil (5-FU), was formulated into FDF in order to prolong GRT, target stomach cancer, and increase drug bioavailability according to Shishu et al. (84). The therapeutic efficacy of FDFs containing 5-FU was checked against benzo $(\alpha)$ pyrene-induced stomach tumors in albino female mice (Balb/C strain). The tumor incidence in mice with FDF was recorded and compared with the conventional tablet dosage form (84).

\section{DIFFERENT CATEGORIES OF BUOYANCY-GENERATING AGENTS}

The general structure of different floating systems using versatile buoyancy mechanisms is illustrated in a schematic diagram (Fig. 3).

Table 1. Summarizes the different parameters affecting the floating behavior of dosage forms based on the type of buoyancy-generating agents.

\section{Gas-generating agents}

The gas entrapped in the dosage form achieves the low density required for buoyancy. Carbonate or bicarbonate salts as sodium bicarbonate $\left(\mathrm{NaHCO}_{3}\right)$ and calcium carbonate $\left(\mathrm{CaCO}_{3}\right)$ are usually incorporated in the formulation alone or blended with organic acids like citric and tartaric acid and then dispersed in the polymeric matrix. This mixture was found to be appropriate for achieving desired buoyancy characteristics. Upon immersion, carbonate or bicarbonate ions start the reaction immediately in vitro with the acidic dissolution media or in vivo with the gastric $\mathrm{HCl}$ and the added organic acids, if present. This reaction generates sufficient amount of $\mathrm{CO}_{2}$ which get entrapped and protected within the gel layer formed by hydrophilic polymer hydration. This leads to decreased density of the tablet (below $1 \mathrm{~g} / \mathrm{cm}^{3}$ ), as a result of which the tablet becomes buoyant. Furthermore, since the $\mathrm{pH}$ of the stomach is elevated under fed state $(\sim 3.5)$, citric or tartaric acid incorporated in the formulation was found to provide sufficiently acidic medium for the salts to react. This will allow the system to float independent of the $\mathrm{pH}$ of the medium $(22,30,85)$. Based on this approach, many research works have formulated gastroretentive dosage forms either as monolithic or multiparticulate systems. Based on GRDDS research, various factors were proven to influence the buoyancy behavior of gas-generating agents containing systems.

\section{Factors affecting system floatation based on gas generation approach \\ The percent of gas-generating agents}

The proportion of gas-generating agents was considered an important factor that should be adjusted to get the least possible lag time with an extended floating duration. Goole et al. (86) confirmed that FLT decreased as the proportion of effervescent agents increased. It was also reported that the gas-generating blend decreases the lag time by accelerating the hydration of the swelling 


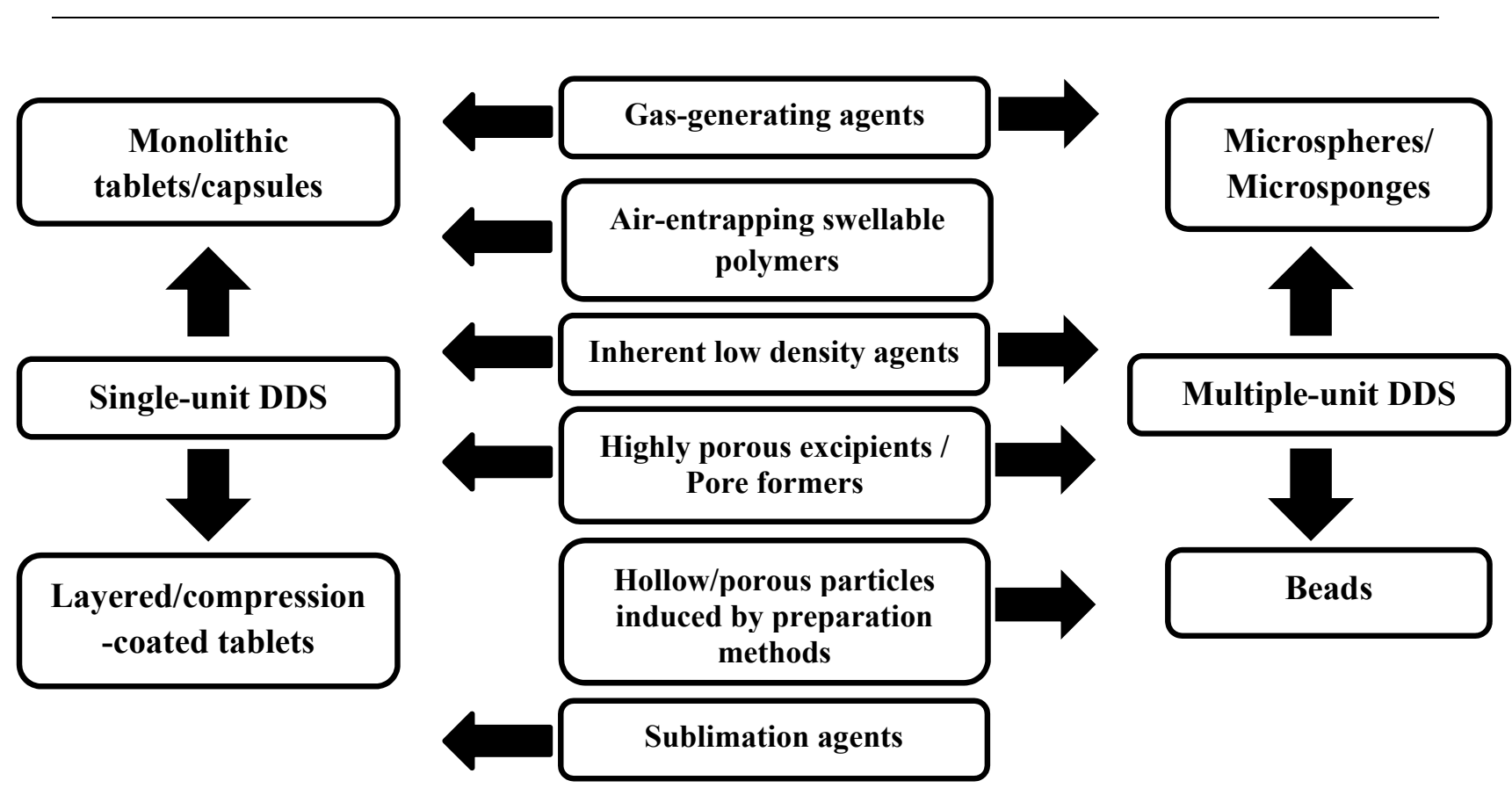

Figure. 3: Schematic diagram showing the general structure of different FDDS using versatile buoyancy mechanisms

polymer, thus allowing a higher floating duration because of the constant generation and subsequent trapping of $\mathrm{CO}_{2}$ (87). Nama et al. (88) prepared an optimized hydrodynamically balanced system (HBS) by adjusting the weight percentage of $\mathrm{NaHCO}_{3}$ used at about $8 \%$ along with hydroxypropyl methyl cellulose (HPMC) K4M polymer. The latter formula gave an in vitro FLT of less than $3 \mathrm{~min}$ with a floating duration extended for $12 \mathrm{~h}$. In vivo X-ray radiographic studies showed the enhanced GRT of the tablet to $220 \mathrm{~min}$ (88). Tadros (45) also developed promising systems exhibiting excellent floating properties with the aid of either $\mathrm{NaHCO}_{3}$ or $\mathrm{CaCO}_{3}$ at $20 \%(\mathrm{w} / \mathrm{w})$ along with $\mathrm{HPMC} \mathrm{K15M}$ and $\mathrm{Na}$ alginate ( $\mathrm{Na}$ alg). Abdominal X-ray imaging of formula containing $\mathrm{NaHCO}_{3}$, loaded with $\mathrm{BaSO}_{4}$, in six healthy volunteers revealed a mean gastric retention period of $5.5 \mathrm{~h}$ (45). Another floating system was prepared based on both citric acid and $\mathrm{NaHCO}_{3}$ at 3.75 and $18.75 \%$ w/w , respectively, as the effervescent base, dicalcium phosphate and HPMC K15M as drug release retardants (89). The formulations were found to have FLT less than $1 \mathrm{~min}$.

Moreover, the gas-generating agents could be also added in a separate layer providing system floatation. Recently, trilayered floating tablets were also prepared using polyethylene oxide (PEO) polymer with middle layer consisting of drug and polymer while outer layers consisted of polymer with $\mathrm{NaHCO}_{3}$. With an increase in the amount of $\mathrm{NaHCO}_{3}$, faster buoyancy was achieved due to the increased $\mathrm{CO}_{2}$ gas formation. The optimized formula exhibited FLT of 3-4 min (90).

Based on gas generation approach, multipleunit FDDS were also prepared. According to Choi et al. (91), the floating calcium alginate beads were prepared by ionotropic gelation of $\mathrm{Na}$ alg with $\mathrm{Ca}^{2+}$ ions, and $\mathrm{CO}_{2}$ was developed from the reaction of $\mathrm{CaCO}_{3}$ or $\mathrm{NaHCO}_{3}$ with acid. The evolving gas permeated through the alginate matrix, leaving gas bubbles or pores, which provided the beads buoyancy. The effects of gasforming agents on bead size and floating properties were investigated. As gas-forming agents increased, the size and floating properties increased. Shishu et al. (84) also demonstrated that the beads containing higher amounts of $\mathrm{CaCO}_{3}$ demonstrated instantaneous, complete, and excellent floating ability over a period of 24 h.

Gellan polysaccharide was also investigated by Rajinikanth and Mishra (44, 76) preparing floating $\mathrm{CaCO}_{3}$-based bead systems. $\mathrm{CaCO}_{3}$ reacts with acidic medium releasing $\mathrm{CO}_{2}$ and $\mathrm{Ca}^{2+}$ ions. The released $\mathrm{CO}_{2}$ was entrapped in the gel network producing buoyant beads. $\mathrm{Ca}^{2+}$ ions produced either from $\mathrm{CaCO}_{3}$ or $\mathrm{CaCl}_{2}$ reacted with gellan producing a cross-linked three-dimensional gel network that restricted 
further diffusion of $\mathrm{CO}_{2}$ drug resulting in an extended period of floating. Increasing both $\mathrm{CaCO}_{3}$ and gellan concentrations significantly reduced FLT. The control beads (without $\mathrm{CaCO}_{3}$ ) sank uniformly in the medium. While those containing $0.5-2 \% \mathrm{CaCO}_{3}$ along with $0.25-1 \%$ gellan showed $71-100 \%$ floatation with $4-10 \mathrm{~min}$ FLT for more than $8 \mathrm{~h}$ in simulated gastric fluid $\mathrm{pH} 1.2$ and for at least $6 \mathrm{~h}$ in rabbits' stomach detected by X-ray radiological method $(44,76)$.

Therefore, it could be concluded that increasing concentration of gas-generating agents to a certain limit reduces significantly the system FLT and extends as well buoyancy duration. While excessive addition of these agents might cause a disruption in dosage form integrity and hence complete loss of floatation capability.

\section{The type of carbonate salts}

According to Choi et al. (91), alginate floating beads containing either $\mathrm{CaCO}_{3}$ or $\mathrm{NaHCO}_{3}$ as gas-forming agents showed different porosity degrees, bead gel strengths and hence altered buoyancy behaviors. Application of $\mathrm{NaHCO}_{3}$ significantly increased porosity and pore diameter in comparison to $\mathrm{CaCO}_{3}$. Incorporation of $\mathrm{CaCO}_{3}$ resulted in smoother beads of higher gel strength than those produced with $\mathrm{NaHCO}_{3}$. This indicated that $\mathrm{CaCO}_{3}$ is superior to $\mathrm{NaHCO}_{3}$ as a gas forming agent in alginate bead preparations (91).

Furthermore, calcium pectinate gel (CaPG) beads containing different carbonate salts types, i.e., $\mathrm{NaHCO}_{3}, \mathrm{CaCO}_{3}, \mathrm{~K}_{2} \mathrm{CO}_{3}$ or $\mathrm{Na}_{2} \mathrm{CO}_{3}$, as a gas-forming agent, showed different floating properties according to Sriamornsak et al. (92). The $\mathrm{CaPG}$ beads containing $\mathrm{NaHCO} 3$ or $\mathrm{CaCO} 3$ were produced instantaneously by ionotropic gelation in which intermolecular crosslinks were formed between the divalent calcium ions and the negatively charged carboxyl groups of the pectin molecules. The $\mathrm{CaPG}$ beads containing $\mathrm{K}_{2} \mathrm{CO}_{3}$ and $\mathrm{Na}_{2} \mathrm{CO}_{3}$ could not be produced as a viscous gel was formed before extrusion through needle. Incorporation of $\mathrm{NaHCO}_{3}$ resulted in porous structured beads, as $\mathrm{NaHCO}_{3}$ can dissociate in neutral medium and readily produce the $\mathrm{CO}_{2}$ gas. While the beads containing $\mathrm{CaCO}_{3}$ showed a dense, non-porous structure due to the insolubility of $\mathrm{CaCO}_{3}$ in neutral medium. Acidification of gelation medium by $\mathrm{HCl}$ increased the pores in the structure of beads containing $\mathrm{CaCO}_{3}$. This was explained by dissociation potency of $\mathrm{CaCO}_{3}$ in acidic medium, i.e., $\mathrm{CaCO}_{3}$ dissociates to release divalent calcium cations contributing to more homogenous $\mathrm{CaPG}$ bead formation and $\mathrm{CO}_{2}$ gas that could be entrapped in the matrix gel beads (92).

\section{The polymer type used}

The choice of the polymeric matrix, needed to retain $\mathrm{CO}_{2}$ gas generated after acid-base interaction, was found to play a role in controlling both FLT and duration. Asnaashari et al. (93) studied the effect of different polymers in preparing floating tablets. $\mathrm{NaHCO}_{3}$ was added as a gas-forming agent along with HPMC, psyllium and carbopol in different concentrations as floating agents that retain the produced gas. These hydrocolloids become hydrated and form a colloid gel barrier around its surface with thickness growing by time. With increasing volume due to hydration, the system shows bulk density less than $1 \mathrm{~g} / \mathrm{cm}^{3}$ and then remains buoyant in the fluid. It was observed that formulae containing HPMC showed prolonged lag times for buoyancy. Adding psyllium to these formulations reduced relative lag times, and kept their proper buoyancy duration times. This could be due to psyllium intrinsic high tendency for gel formation (higher than HPMC). The study also showed that carbopol regardless of the short lag time for floating, could not prepare good buoyancy attributed to rapid hydration, gel formation and erosion rate of carbopol (93).

Moreover, Patel et al. (94) observed that the type of filler and the ratio of Gelucire $43 / 01$, as a hydrophobic meltable binder, to HPMC K4M had significant influence on buoyancy lag time. Recently, Rao and Lakshmi (21) designed a floating system using three polymers xanthan gum, HPMC K15M and HPMC K4M, and $\mathrm{NaHCO}_{3}$ as the gas-generating agent. Based on the results, tablets prepared by xanthan gum was the best formulation with an in vitro FLT less than $1 \mathrm{~min}$ and buoyancy was extended for more than $12 \mathrm{~h}$. This was attributed to the swelling behavior of the prepared formulae based on the formation of hydrogel by the hydrophilic polymers used, their concentrations and molecular weights (21).

\section{The type and level of polymeric coating}

Floating drug delivery systems, consisting of gasgenerating agent within the core and covered by polymeric film coat, showed variable buoyancy behaviors depending on the type and concentration of polymer in coat. Blends of a water-insoluble polymer and a hydrophilic polymer at different ratios were tried (28). The addition of soluble polymers, such as HPMC, polyethylene glycol (PEG) 6000, PEG 600, and 
Kollicoat ${ }^{\circledR}$ IR, greatly increased the water uptake ability of the insoluble polymers (Eudragit ${ }^{\circledR} \mathrm{NE}$, RS, and RL; Surelease ${ }^{\circledR}$; and Kollicoat ${ }^{\circledR}$ SR) and caused them to immediately initiate the effervescent reaction and float, but the hydrated films should also be impermeable to the generated $\mathrm{CO}_{2}$ to maintain floatation and sufficiently flexible to withstand the pressure of $\mathrm{CO}_{2}$ to avoid rupturing (95). The increased amount of a gas forming agent did not affect time to float while increasing coating level of gas-entrapped membrane increased FLT (96).

\section{The compression pressure}

Jiménez-Martínez et al. (97) showed that Metolose SH 4000 SR matrices compacted at $55 \mathrm{MPa}$ float in the dissolution medium for more than $8 \mathrm{~h}$ while those compacted at $165 \mathrm{MPa}$ float only when $\mathrm{NaHCO}_{3}$ is included in the formulation due to increase in the matrix hydration volume. The matrix density was lower when compacted at $55 \mathrm{MPa}$.

\section{The method of preparation}

A study investigated the physicochemical properties of hot-melt extruded (HME) and directly-compressed tablets containing a blend of Eudragit ${ }^{\circledR}$ RS PO and $\mathrm{NaHCO}_{3}(98)$. The crosssectional morphology of the HME tablets showed a porous structure since $\mathrm{CO}_{2}$ gas was generated due to the thermal decomposition of $\mathrm{NaHCO}_{3}$ in the softened acrylic polymers at elevated temperature during the extrusion process. The HME tablets floated on the surface of the media for $24 \mathrm{~h}$ while directly-compressed tablets showed no buoyancy in the dissolution media (98).

Sriamornsak et al. (92) prepared CaPG beads containing carbonate salts showed different floating properties depending on the drying method. Incorporation of $\mathrm{NaHCO}_{3}$ resulted in porous structured beads while the beads containing $\mathrm{CaCO}_{3}$ showed the dense, non-porous structure if the beads were air-dried. Freeze-dried beads demonstrated more porous structure and hence higher floating ability than that of air-dried beads.

\section{Combinatorial factors}

Krögel and Bodmeier (125) were the first adopting a floating drug delivery system based on a reservoir system consisting of a drug-containing effervescent core and a polymeric coating. The time to flotation could be controlled by several factors; the composition (type of filler, concentration of effervescent agents), hardness of the tablet core, and the composition (type of polymer and plasticizer) and thickness of the coating layer (125). The influence of three commonly used fillers, microcrystalline cellulose, dibasic calcium phosphate and lactose, on the floating behavior of the coated tablets was investigated. Tablets containing lactose floated earlier than tablets prepared with the inorganic filler dibasic calcium phosphate. This could be explained by the different densities. In addition, lactose has a higher water solubility and thus osmotic activity, resulting in a faster uptake of the medium into the core by diffusion through the coating. Microcrystalline cellulose, an insoluble filler with a high water uptake and disintegration capability, resulted in the rupturing of the coating and disintegration of the tablet. $\mathrm{CO}_{2}$ did not accumulate under the coating and escaped through the ruptured films, floating was therefore not achieved. Therefore, lactose was the filler of choice. The higher amount of effervescent agent caused faster and higher $\mathrm{CO}_{2}$ generation. However, at very high concentrations of the effervescent agents, the coating was less stable due to the increased inner pressure, and the risk of rupturing of the polymeric coating was higher. Moreover, increasing the hardness of the tablet core from 30 to $130 \mathrm{~N}$ resulted in an increase in the time to flotation. A lower hardness resulted in tablets with a higher porosity, which facilitated the water penetration and therefore the effervescent reaction. A polymer coating with a high elongation value and high water- and low $\mathrm{CO}_{2}$ permeability was selected (Eudragit ${ }^{\circledR}$ RL/acetyltributyl citrate) in order to initiate the effervescent reaction and the floating process rapidly. With increasing the level of the outer polymeric coating, the floating started later due to the delayed water penetration through the thicker coating $(40,126)$.

Additionally, Khan et al. (127) have designed a novel floating elementary osmotic pump tablet (FEOPT). The FEOPT consisted of an osmotic core (drug, mannitol, and hydrophilic polymers) coated with a semipermeable layer (cellulose acetate) and a gas-generating gelling layer $\left(\mathrm{NaHCO}_{3}\right.$ with hydrophilic polymers) followed by a polymeric film (Eudragit RL 30D). The effect of formulation variables such as concentration of polymers, type of diluents, and coat thickness of semipermeable membrane was evaluated in terms of FLT and duration of floatation. All the developed FEOPT showed FLT of less than 8 min and floating duration of $24 \mathrm{~h}$ (127). 


\section{Air-entrapping swellable polymers}

One of the approaches to formulate FDDS involves intimate mixing of drug with a gelforming hydrocolloid. Buoyancy of the dosage form is governed by the swelling (hydration) of the hydrocolloid particles on the system surface when it contacts the gastric fluids, resulting in an increase in the bulk volume. Moreover, the presence of internal voids in the dry center (porosity) affects the system floatation. These two factors are essential for the dosage form to trap air and hence to acquire bulk density less than 1 and so remain buoyant on the gastric fluid (128). In addition, the gel structure acts as a reservoir for sustained drug release since the drug is slowly released by a controlled diffusion through the gelatinous barrier $(6,129)$. Among the variables affecting the floating pattern of systems containing these gel-forming hydrocolloids; the type of polymer, drug and other excipients incorporated.

\section{Effect of polymer type on floating behavior}

The most commonly used gel-forming or highly swellable polymers are cellulose type hydrocolloids, polysaccharides, and matrixforming polymers such as polycarbonate, polyacrylate, polymethacrylate and polystyrene (130). Alginate and HPMC were previously reported their ability to float on gastric contents and provided sustained release characteristics (99, 101). Washington et al. (131) suggested that the formulation consisting of a mixture of alginate, forms a gel of alginic acid. The gel becomes buoyant by entrapping the gas bubbles and floats on the gastric contents as a viscous layer. Furthermore, cellulose ether polymers (HPMC) have a bulk density of less than unity in gastric fluids $(132,133)$.

Alginate and chitosan (Cs) blends were also reported in gelation and air entrapment within the dosage form (16). The buoyancy was not affected neither by the molecular weight or degree of deacetylation of $\mathrm{Cs}$ added nor the variation in $\mathrm{Cs}$ particle size. Floating was not observed for alginate containing 5\% chitin, curdlan, sodium dextran sulfate, pullulan or xylan, instead of $\mathrm{Cs}$ (16).

Glyceryl esters of fatty acids such as glyceryl monooleate (GMO) belong to class of polar amphiphilic lipids which swell in water and form various kinds of lyotropic liquid crystals (134). Swelling of GMO matrix system due to water uptake reduces its density and hence assists its floatation for a prolonged period of time (102).
Various grades of swellable polymers (PEO WSR 1105, WSR 301, WSR 303, WSR $60 \mathrm{~K}$, WSR N80 and HPMC K4 M) were used by physical blending with the drug in varying ratios according to Ali et al. (56). From the in vitro buoyancy studies it was observed that $\mathrm{PEO}$ WSR 60K, PEO WSR 303 and HPMC K4 M containing formulations showed good buoyancy with floatation time up to $12 \mathrm{~h}$. In vivo studies using $r$-scintigraphy showed that the selected HBS formula remained buoyant during $5 \mathrm{~h}$ of study in rabbits.

A comprehensive study was conducted to investigate the effects of carrageenans and HPMC on the properties of HBS (135). Matrices based on carrageenans subjected to rapid hydration and erosion, were not able to maintain satisfactory floating properties for a sufficiently long period of time. The application of carrageenans in mixtures with HMC promoted water uptake by HBS formulations (135).

Recently, Dey et al. (100) developed a floating matrix tablet using polymer blend of xanthan gum and guar gum. The optimized formulation containing $20 \%(\mathrm{w} / \mathrm{w})$ of polymer blend and 50:50 ratio of both gums was able to float more than $12 \mathrm{~h}$. In vivo retention studies in rabbit stomach showed the gastric residence of tablet up to $6 \mathrm{~h}$.

Effect of drug and additives on floating behavior Physiochemical properties of the drug and additives such as PEG 4000, PEG 10000, and stearic acid significantly affected floatability of swellable systems according to Kumar et al. (102). It was observed that the water uptake increases with increase in the loading of polar drug (Chlorpheniramine maleate) and decreases with non-polar drug (Diazepam). Buoyancy lag time was found to increase with increase in stearic acid and PEG amount. Molecular weight of PEG did not significantly affect FLT. The increase in lag time was more in case of stearic acid due to reduction in water uptake caused by hydrophobic nature of stearic acid and hence reduced matrix swelling tendency (102). The effect of PEG on matrix buoyancy could be attributed to the following reasons: (1) at low concentration, PEG as a hydrophilic excipient increases water uptake and forms a porous, non-transparent, low-density matrix, (2) while at higher concentration, erosion of the matrix occurred from the surface, and even breaking of the matrix into small aggregates. The buoyancy is favored by increase in the porosity, whereas opposed by the increase in viscosity of aqueous filled channels. Similar effect was 
observed with incorporation of PEG 10000, but the extent of floatation at lower concentrations was comparatively less. It might be attributed to the high molecular weight and less polarity of PEG 10000 yielding the formation of less spongy matrices (102).

\section{Inherent low density agents}

Among the agents used to impart the dosage form a low bulk density are the substances characterized by an inherent low density property. The concentration of such substances plays an important factor in buoyancy of the drug delivery system. Murata et al. (16) was among the leading incorporating a low density excipient in a multiunit floating system. The beads are formed by the ionotropic gelation between alginate and calcium pantothenate in the presence of a vegetable oil (ALGO). The concentration of oil as low density agent used was proven to influence the time to float. The oil-free beads sank in water, physiological saline or $\mathrm{HCl}$ solution mimicking gastric juice. However, the ALGO containing $30 \%$ olive oil floated in these solutions. ALGO containing 10 or $20 \%$ oil firstly sank in water then gradually floated. ALGO containing $40 \%$ olive oil was not used because the oil began to leak from the beads at this high concentration (16).

Sriamornsak et al. $(104,105)$ adopted an emulsion-gelation method to prepare oilentrapped calcium pectinate gel (EMG) beads capable of floating in the gastric condition. The blank and loaded gel beads containing edible oil were prepared by either being gently mixed or homogenized an oil phase and a water phase containing pectin, and then extruded into $\mathrm{CaCl}_{2}$ solution with gentle agitation at room temperature. Pectin helped to emulsify the mixture of water and oil phases during the homogenization process. The prepared emulsion containing pectin was gelled by the action of calcium. The effect of selected factors, such as type of oil (e.g., light mineral, olive, sunflower, peppermint, sesame, rice, soybean and corn oil), percentage of oil (10-30\%), and type of pectin based on the degree of esterification on beads morphology and floating properties was investigated. The EMG beads were more spherical and exhibited a smoother surface than conventional calcium pectinate beads. The conventional calcium pectinate beads (with no drug) made of low methoxy pectin did not float in SGF. In contrast, if a sufficient amount of oil was added (i.e. $10 \%$ mineral oil, $20 \%$ olive oil or peppermint oil), the EMG beads floated immediately and remained floating for $24 \mathrm{~h}$ attributed to the low relative densities of the oils. Drug-loaded EMG beads, containing the same percentage of the latter oils, showed a delay in floatation compared to unloaded beads. However, the beads were then afloat after the drug was released from the beads. The EMG beads treated with glutaraldehyde and contained additives such as PEG 10000, Eudragit ${ }^{\circledR}$ L 100 or glyceryl monostearate showed good in vitro floating behavior in SGF $(104,105)$. Liquid paraffinentrapped alginate-based floating system was also prepared by Malakar et al. (103) through the same latter method for gastro-retentive delivery. The effect of process variables; drug to polymer ratio by weight, and liquid paraffin to water ratio by volume on beads density and floatation was optimized. The optimized beads showed density of $0.90 \mathrm{~g} / \mathrm{cm}^{3}$, with FLT of $8.45 \mathrm{~min}$ and floated well over $12 \mathrm{~h}$ in simulated gastric fluid $(\mathrm{pH} 1.2)$ (103).

Some researchers combined commonly used polysaccharides; either alginate and pectin (136) or alginate and casein (137) in the same oilentrapped floating microbeads prepared by emulsion gelation method $(136,137)$. Other authors used a mixture of low density excipients such as isopropyl myristate (oil) and Gelucire $\mathbb{}$ $43 / 01$ (lipid) incorporating in alginate beads (138).

On the other hand, Ishak et al. (74) prepared alginate beads by the aid of the known hydrophobic lubricant magnesium stearate via the ionotropic gelation method. The bead formula containing 5\% magnesium stearate showed immediate buoyancy (74).

Furthermore, a developed low-density tablet form using a hydrophobic dusty powder silicon dioxide (Aerosil R972) was prepared by Sauzet et al. (29). The increase of active ingredient percentage led to an increase of the tablet density. While, an increase of Aerosil R972 percentage had a strong influence on decreasing system density (29).

A recently research work adopted by Eberle $e t$ al. (106) incorporated functionalized $\mathrm{CaCO}_{3}$ (FCC) in a floating gastroretentive drug delivery system (GRDDS). The characteristically low apparent density of the excipient (approx. $0.6 \mathrm{~g} / \mathrm{cm}^{3}$ ) in addition to its inherent high porosity enabled a mechanism of floatation. In SGF, the FCC-based tablets showed instant floatation.

\section{Highly porous excipients / Pore formers}

The use of highly porous ingredients in dosage forms was investigated to impart a low density hence floability suitable for gastroretention for the 
systems that contain. The addition of pore forming agents was also reported to give the same effect.

In this context, Bulgareli et al. (37) prepared casein-gelatin beads relying on casein emulsifying properties that cause air bubble incorporation and the formation of large pores in the beads. They have been prepared by emulsification extraction method and cross-linked with d,l-glyceraldehyde in an acetone-water mixture 3:1 (v/v). Casein was considered suitable for the formation of an air reservoir for FDDS (37).

Streubel et al. (108) was the first using the highly porous polypropylene foam powder (Accurel ${ }^{\circledR}$ MP 1002 and MP 1000) in floating polymeric microparticles (MPs). The MPs were irregular in shape and highly porous. Good in vitro floating behavior was observed as more than $83 \%$ of the particles kept floating for at least $8 \mathrm{~h}$. The polymer partially covers the pores and entraps air within the system. Upon exposure to aqueous media the entrapped air is only slowly removed from the system leading to extended floating times (108). Furthermore, the same authors employed the highly porous foam powder in monolithic FDDS with matrix-forming polymers such as HPMC, polyacrylates, $\mathrm{Na}$ alg, corn starch, carrageenan, gum guar and gum arabic. All foam powder-containing tablets remained floating for at least $8 \mathrm{~h}$ in $0.1 \mathrm{~N} \mathrm{HCl}$ at $37^{\circ} \mathrm{C}(107)$.

Calcium silicate (Florite $\mathrm{RE}^{\circledR}$ ) as a porous carrier was also used to develop floating microspheres (111). The MPs were prepared by emulsion solvent diffusion technique and Eudragit $\mathrm{S}$ as polymer. The MPs were found to be regular in shape and highly porous. All the calcium silicate-based formulations showed good floating ability $(84 \pm 6.0 \%)$. More than $80 \%$ of the particles kept floating for at least $10 \mathrm{~h}$ (111). Other groups of researchers developed similar floating multiparticulate systems using porous calcium silicate $(109,110)$.

Furthermore, polyethylene glycol (PEG) is used as pore forming agent that induces buoyancy (112). Floating MPs were prepared by novel solvent evaporation-matrix erosion method using ethyl cellulose (EC) and polyethylene glycol (PEG) blend. When the microspheres are dispersed in SGF, due to high water solubility, PEG goes into solution forming pores on microspheres due to matrix erosion. This phenomenon makes the microspheres to float. The formulated microspheres could float within 5-10 min depending upon the \% of PEG present in the microspheres. As the \% of PEG increases, floatation time reduces. EC MPs prepared with $20-33.3 \%$ of PEG showed floatation for $10 \mathrm{~h}$. The presence of pores on the surface of floating microspheres, due to matrix erosion, are responsible for floating ability (112).

Li et al. (113) recently developed a novel gastro-floating multiparticulate system based on a porous and low-density matrix core with excellent floatability. The porous matrix core was achieved by the complete release of mannitol as bulk water soluble excipient from EC coated beads. The optimized formulation floated on the dissolution medium for at least $12 \mathrm{~h}$ without lag time to float (113).

\section{Hollow/porous particles induced by preparation methods}

Different formulation techniques of multiparticulate systems were reported to produce hollow or porous particles suitable to be buoyant on dissolution or gastric media.

\section{Emulsion-solvent diffusion method}

Microballoons (MB) with hollow structure were firstly prepared by Kawashima et al. (117) as a novel multi-unit floating device by the emulsionsolvent diffusion method. The model drug and an acrylic polymer were dissolved in an ethanoldichloromethane mixture and then poured into an aqueous solution of polyvinyl alcohol (PVA) with stirring to form emulsion droplets. The use of two solvents (dichloromethane and ethanol) having different rates of diffusion led to the formation of a hollow core responsible for the flotation ability of the microspheres. By changing the polymer concentration and the ratio of ethanol to dichloromethane, different drug contents were embedded in $\mathrm{MB}$ shell. With higher polymer ratios, the internal cavity volume of the MB was increased. Most of the MBs were floatable in vitro for $12 \mathrm{~h}$ when immersed in aqueous media. An in vivo radiographical study proved that MBs orally administered to humans were retained in the upper part of the stomach for over $3 \mathrm{~h}$ against peristaltic action (117). Similar approach was also developed by El-Kamel et al. (118). Sato et al. (115) found that both the preparation temperature and the MB surface smoothness determined the formation of cavity inside the microsphere and hence its buoyancy. At low temperatures (20 or $30^{\circ} \mathrm{C}$ ), a slow rate of organic solvent evaporation led to formation of porous microspheres as dichloromethane remained in the droplets preventing formation of a hard polymer shell. On the other hand, an increase in evaporation rate of 
dichloromethane caused the formation of a large depression within microspheres. Gradual evaporation of dichloromethane at $40^{\circ} \mathrm{C}$ appeared necessary for cavity formation in MBs (115). The effect of MB size on its in vivo buoyancy behavior was also studied by Sato et al. (114) showing that MB with particle size ranged from $500-1000 \mu \mathrm{m}$ exhibiting high buoyancy compared to $\mathrm{MB}$ with particle size $<500 \mu \mathrm{m}$ (114).

Relying on the principle adopted previously by Kawashima et al. (117), Liu et al. (116) developed hollow-bioadhesive microspheres consisted of a mixture of ethylcellulose and Eudragit ${ }^{\circledR}$ EPO and then coated with glyceryl monooleate (GMO) as bioadhesive polymer in situ. More than $80 \%$ of the hollow microspheres continued to float for at least $10 \mathrm{~h}$ in vitro. After the hollow microspheres were coated with GMO, the percentage floating at the SGF surface decreased slightly because of some microsphere aggregation, but nevertheless remained high (116).

\section{Ionotropic gelation method}

According to El-Gibaly (31), floating microcapsules (MCs) were prepared by the ionic interaction of $\mathrm{Cs}$ and a negatively charged surfactant, sodium dioctyl sulfosuccinate (DOS). The use of DOS solution in coagulation of Cs produced well-formed MCs with round hollow core. Most of the hollow MCs tended to float over simulated gastric fluid (SGF) for more than $12 \mathrm{~h}$. The characteristics of floating MCs generated compared with the conventional non-floating microspheres manufactured from $\mathrm{Cs}$ and sodium tripolyphosphate (TPP) were also investigated. The use of TPP solution in coagulation of Cs induces the formation of a microsphere structure in which a core is not defined. All TPP/Cs microspheres displayed essentially poor spherical particles with numerous surface cracks and pores compared with DOS/Cs MCs (31).

\section{Solvent evaporation method}

Polycarbonate (PC) microspheres were developed by a solvent evaporation technique (119). Drugloaded microspheres were found to float on SGF. It was shown that the rapid evaporation of dichloromethane from the dispersion produces cavities and pores in the microspheres which render them hollow and floating in nature (119). Joseph et al. (120) prepared similar hollow PC microspheres.

\section{Freeze-drying method}

Calcium alginate multiple-unit FDDS was developed by freeze-drying method (121). Spherical beads were prepared by the precipitation of calcium alginate aqueous solution of calcium chloride. The beads are then separated, snap-frozen by liquid nitrogen, and freeze-dried at $-40^{\circ} \mathrm{C}$ for $24 \mathrm{~h}$. This treatment leads to the formation of a porous system due to the ice crystals, formed by freezing, that sublimate leaving gaps or pores in their place. The in vivo behavior of this system compared to a multipleunit non-FDF prepared from the same material was investigated (52). Prolonged GRTs of over $5.5 \mathrm{~h}$ were observed in volunteers taking the radiolabelled floating formulations by $\gamma$ scintigraphy. In contrast, the non-floating beads displayed short GRTs, with a mean onset emptying time of $1 \mathrm{~h}$ (52).

\section{Foam solution-based method}

According to Yao et al. (59), a simple and rapid method was established to prepare a novel kind of inner-porous floating beads. The beads were prepared by dripping the foam solution into $\mathrm{CaCl}_{2}$ solution using disposable syringe needle. The foam solution was consisting of numerous microbubbles with poloxamer 188 as foaming agents and alginate as foaming stabilizer along with the drug. The presence of alginate increased significantly the foamability of poloxamer 188 . Addition of the non-ionic surfactant poloxamer 188 leads to the formation of a surfactantpolymer complex through interactions between alginate and surfactant, which contributes to foamability and foam stability. The SEM crosssection pictures of the beads showed that they were inner-porous and composed of bubbles with very thin wall bubbles stacked together. The floating beads showed good buoyancy as most beads could float in the stomach for more than $6 \mathrm{~h}$ by $\gamma$-scintigraphic images (59).

\section{Quasi emulsion-solvent diffusion method}

A modified quasi emulsion solvent diffusion method was recently used to prepare floating microsponges by the aid of sodium chloride solution $(\mathrm{NaCl})$ as porogen (122). The organic phase was consisting of polymeric solution of EC and Eudragit S 100 along with the drug in a mixture of ethanol and dichloromethane. The latter organic phase is dispersed into aqueous phase containing PVA, quasi emulsion droplets are formed due to increase in interfacial tension between ethanol and PVA. The diffusion of ethanol from the droplets into the aqueous phase 
(PVA) facilitates the counter diffusion of PVA into the droplets, which increases the viscosity of polymeric solution containing EC, Eudragit S 100 and drug within the droplets. Water soluble $\mathrm{NaCl}$ effuses into PVA solution leaving polymer matrix behind and the interconnected pores are formed during the formation of microsponges. The microsponges formed with high level of EC and PVA were more buoyant than those with low level. The pharmacokinetic evaluation of the optimized formula in rabbits revealed 10-fold increase in bioavailability as compared to free drug (122).

\section{Electrospray method}

A novel low density system of porous Eudragit ${ }^{\circledR}$ RS (ERS) MPs was recently fabricated by Hao et al. via electrospray method $(17,123)$. ERS was dissolved in dichloromethane at different concentrations along with the drug. The solution was supplied by a syringe pump for spraying from the grounded nozzle. The nozzle was connected to a positive electrode of a high-voltage power supply helping the smaller sized droplets to break up into micro-sized droplets. Aluminum foil was placed perpendicular to the nozzle as collector. As the solvent of the droplets will evaporate before reaching the collector, thus the solid particles can be obtained directly by electrospray method. The porous MPs would be obtained by electrospray method due to the fast evaporation of solvent. Buoyancy of porous MPs decreased as ERS concentration was increased, which may due to the increase in the density of MPs. More than $85 \%$ of porous MPs were floated in all the formulations at $12 \mathrm{~h}$. $\gamma$-scintigraphy study in vivo demonstrated that ${ }^{131}$ I-labeled MPs retained in stomach for over $8 \mathrm{~h}$, and about $65.50 \%$ radioactive counts were finally detected in the gastric region (17).

\section{Sublimation substance}

Camphor was used as the sublimation material in a novel floating system as it changed to pores in the tablet during the sublimation process. The GR tablets have a highly porous morphology. The prepared tablets floated for over $24 \mathrm{~h}$ and had no FLT. However, as the amount of camphor in the tablet matrix increased, the crushing strength of the tablet decreased after sublimation (124).

\section{Dual floating aids}

A number of authors adopted FDDS relying on more than one buoyancy aid; such as air from swellable polymers combined with oil as low density material or with a gas-generating agent. A controlled-release GRDDS was firstly formulated by Desai and Bolton (51) based on both air and oil entrapped in the agar gel network. $\gamma$ scintigraphic studies for a floating and a heavy non-floating tablet, under fasting and non-fasting conditions, showed that the presence of food significantly increased GRT for both tablets, and tablet density did not surprisingly appear to make a difference in GRT. However, the positions of the floating and non-floating tablets in the stomach were very different (51).

The buoyancy of tablets prepared by Chen et al. (139) was based on both $\mathrm{NaHCO}_{3}$ as gasgenerating agent and air entrapped within swellable polymers; hydroxyethyl cellulose (HEC) and sodium carboxymethyl cellulose (NaCMC). An appropriate ratio of $\mathrm{HEC}$ to $\mathrm{NaCMC}$, the addition of $\mathrm{NaHCO}_{3}$, as well as compression at lower pressures resulted in the tablets floating over SGF for more than $16 \mathrm{~h}$. The mean bioavailability from the floating tablet was approximately $164 \%$ relative to the immediaterelease product (139). Similarly, Jagdale et al. (140) formulated floating tablets based on a mixture of $\mathrm{NaHCO}_{3}$ and citric acid combined with a blend of polymers Xanthan gum and Locust bean gum. Floating behavior was achieved due to $\mathrm{CO}_{2}$ generated from the acid-base interaction in addition to polymer swelling property (140).

$\mathrm{Hu}$ et al. developed floating tablets employing hydroxypropyl methylcellulose K4M (HPMC) as hydrophilic gel material, $\mathrm{NaHCO}_{3}$ as gasgenerating agent and hexadecanol as floating assistant agent (141). The prepared tablets floated within $3 \mathrm{~min}$ and maintained for more than $24 \mathrm{~h}$.

Paula et al. (142) prepared a polymeric floating system composed of Alginate and Cashew gum (CG), loaded with an essential oil (Lippia sidoides-Ls) by ionotropic gelation. The beads produced with carbonate and Ls at high level contents exhibited good floatability for up to 5 days (142). Other authors $(143,144)$ developed oil-entrapped buoyant gellan-based beads. Buoyant beads of gellan were developed by inotropic gelation technique using $\mathrm{CaCO}_{3}$ as gas forming agent and the drug polymer dispersion was emulsified with mineral oil and blended with HPMC or carbopol 934. The beads showed comparatively better residence and higher drug concentration in the gastric mucosa of the treated animals $(143,144)$.

Another research group developed a dualmode floating system based on both gasgenerating agent and sublimating agent (145) showing instant floatation without lag time in vitro (145). 
Although the combination of more than one floating aid was predicted to improve buoyancy behavior of different FDDS, yet FLT and duration don't differ significantly compared to a single floating aid. Lack of comparative studies for systems containing single and multiple buoyancygenerating agents might be the reason for inability to conclude the real advantages of dual floating aids.

\section{BUOYANCY-GENERATING AGENTS in MARKETED FDDS}

Although floating GR systems have been in focus of interest of many researchers for the last three decades, marketed products are still limited in number. Few marketed FDFs are gas-generating agent-based products. Topalkan ${ }^{\circledR}$ and Liquid Gaviscon ${ }^{\circledR}$ are well-established marketed antacid floating products produced by Pierre Fabre ( France) and Glaxosmithkline (USA), respectively. These products relied on the presence of carbonate and bicarbonate salts in alginate dispersion. The polymer is subjected to in situ gelation by the divalent/polyvalent cations present in stomach as well as in formula. Moreover, the interaction of the carbonate and bicarbonate salts with the stomach acid leads to the evolution of $\mathrm{CO}_{2}$ entrapped within the viscous cohesive gel. The floating polymeric gel sheet formed was usually described as 'raft-forming system' (146).

Furthermore, Baclofen ER ${ }^{\circledR}$ used as muscle relaxant is manufactured as FDF by Sun Pharma Advanced Res Co Ltd. The GR controlled drug delivery system comprises a controlled release core composed of a highly swellable polymer and a gas generating agent capable of swelling and achieving floatation rapidly while maintaining its physical integrity in GIT for prolonged periods in addition to a rapidly releasing coat containing the drug as in the core providing a biphasic drug release in GIT (147) .

Almagate Flot-coat $\AA$ is another marketed antacid product produced by Laboratorios Almirall relying on the inherent low density of a hydrophobic agent. Coating the granulate particles of the antacid product with selected hydrophobic excipients increases the lipophilicity as well as delays reaction with hydrogen ions without altering the intrinsic acid neutralising properties. The prolonged residence time is a function of the lipophilicity of the particles which preferentially adhere to the gastric mucosa or form a layer on the surface of the gastric contents. The antacid is then slowly liberated, reacts with hydrogen ions in the vicinity, protects the mucosa and its emptying from the stomach is delayed in spite of peristaltic movements (148).

Valrelease ${ }^{\circledR}$ and Madopar ${ }^{\circledR}$ HBS are considered as floating capsules marketed by Hoffmann-LaRoche (USA). The former product contains $15 \mathrm{mg}$ diazepam as antianxiety but the latter contains $100 \mathrm{mg}$ L-dopa and $25 \mathrm{mg}$ benserazide used in treatment of Parkinson's disease. The buoyancy of these products is based on air entrapped by swellable polymers providing HBS systems in addition to fatty materials to regulate floatation. These hydrodynamically balanced capsules acquire a density of less than one remaining buoyant on the gastric fluid (101). Cytotec ${ }^{\circledR}$ is another marketed product relying on the same category of buoyancy agents. It is a 100 or $200 \mu \mathrm{g}$ misoprostol-containing floating SR capsule marketed by G.D. Searle Co. (now Pfizer, USA). The dosage form comprises a noncompressed bi-layer formulation in a capsule; one layer comprising a drug release layer and the other a buoyant layer, providing extended GRT of the dosage form so that substantially all drug is released in the stomach over an extended period. The floating layer includes a polymer having the properties of a gelling agent and which upon contact with gastric fluid hydrates and forms a gelatinous barrier or mass filled with air responsible to decrease the system density. The floating layer provides buoyancy to the dosage form as well as capsule diametric increase as the capsule attains a larger diameter in relation to its original size (149). Moreover, Conviron ${ }^{\circledR}$ is another example of marketed colloidal gelforming FDDS that contains ferrous sulphate produced by Ranbaxy (India).

Additionally, Depomed, Inc. formulated few products based on patented Acuform ${ }^{\circledR}$ drug delivery technology. This technology depends on a combination of PEO and HPMC as a matrix for a swellable sustained-release tablet providing the ability to swell for GR and to control drug release. The swelling behavior of PEO is retained but balanced against the erosion behavior of HPMC which modulates the extent and progress of swelling (150). Acuform's unique swelling polymers allow the tablet to be retained in the stomach for approximately $8-10 \mathrm{~h}$. Proquin XR ${ }^{\circledR}$ is Depomed's first FDA approved product, and it is a testament to the benefits of GR Acuform drug delivery technology. Proquin XR $®$ is a once-daily extended-release formulation of ciprofloxacin $\mathrm{HCl}$ and is intended to treat uncomplicated urinary tract infections.

Acuform technology is also used in the formulation of three additional products marketed 
by Depomed's partners: Santarus' Glumetza $^{\circledR}$ (metformin $\mathrm{HCl}$ extended release tablets), Merck's Janumet ${ }^{\circledR}$ XR (sitagliptin and metformin $\mathrm{HCl}$ extended-release) and Janssen's Nucynta ${ }^{\circledR}$ ER (tapentadol extended-release tablets).

Recently, Depomed apply the same technology in the formulation of once-daily Gralise $^{\circledR}$ (gabapentin) tablets. This is an investigational extended release and gastric retained formulation of gabapentin, an FDAapproved product for the treatment of Postherpetic Neuralgia (PHN). PHN is a persistent neuropathic pain condition caused by nerve damage after a shingles, or herpes zoster, viral infection. The formulation of once- or twicedaily gabapentin is particularly challenging since gabapentin is absorbed through an active transport mechanism which is concentrated in the upper gastrointestinal tract. Therefore a gastric retained formulation of gabapentin may demonstrate an improvement in delivering drug to these active transport sites compared to a more traditional extended release technology (151).

\section{CRITICAL ASSESSMENT}

Several approaches have been investigated and developed for GR of dosage forms. This was for purpose of controlling drug delivery, allowing more drug absorption extent for those having narrow therapeutic window, improving local gastric treatment and reducing drug instability/insolubility in high intestinal $\mathrm{pH}$. Buoyancy is one of the promising methods used for stomach specific drug delivery. Various aids were adopted in order to decrease the density of the dosage form hence enhance its floatation. These floating agents were based either on gas generation, air filling, inherent low density, porosity or sublimation. The assessment of the floating behavior for such developed systems is mandatory either in vitro or in vivo proving their GR tendency by direct or indirect techniques. It is worth to notice that only few of these buoyancygenerating agents provided an instantaneous floatation to the drug delivery system without a delay time; primarily the hollow particles prepared by different formulation techniques. Other floating aids suffered with variable degrees lag time depending on different preparation factors; concentration, type, compression force, additives. Furthermore, the floating duration of all buoyant dosage forms is generally considered unpredictable and inconsistent owing to several technical and physiological influences; mainly the erosion rate of polymer incorporated within the system and the variable gastric emptying rate in fasted and fed state, respectively.

On the other hand, it is perceptible that the majority of marketed GR floating products are monolithic relying on gas-generating agents, swellable polymers or combination of both. In addition, it is well known that the multiparticulate systems are advantageous compared to single-unit ones in; achieving a more predictable drug release profile, preventing all-or-none gastric emptying, allowing co-administration of incompatible actives or units with different release profiles. Despite these, there is no floating multiple-unit GRDDS such as microparticles, minicapsules or beads in the market, yet.

Therefore, future development approaches should focus on:

- A deep in vivo study resolving the dilemma of unpredictable gastric emptying of FDDS with reviewing the actual effect of fed and fasted conditions on their GRT.

- Increasing the propensity of the pharmaceutical industry in manufacturing more FDFs especially multiparticulate FDDS in order to solve drug-related problems.

\section{REFERENCES}

1. Jolliffe DM. Practical gastric physiology. Continuing Education in Anaesthesia, Critical Care \& Pain j 2009;9(6):173-7.

2. Kong F, Singh R. Disintegration of Solid Foods in Human Stomach. J Food Sci. 2008;73(5):R67-80.

3. Fell JT. Targeting of drugs and delivery ystems to specific sites in the gastrointestinal tract. J Anat. 1996;189:517-9.

4. Siegel J, Urbain J, Adler L, Charkes N, Maurer A, Krevsky B, et al. Biphasic nature of gastric emptying. Gut. 1988;29(1):85-9.

5. Versantvoort C, Kamp EVd, Rompelberg C. Development and applicability of an in vitro digestion model in assessing the bioaccessibility of contaminants from food. Bilthoven, The Netherlands2004. Report No.: RIVM report $320102002 / 2004$.

6. Singh B, Kim K. Floating drug delivery systems: an approach to oral controlled drug delivery via gastric retention. J Control Rel. 2000;63:235-59.

7. Sugiharaa $\mathrm{H}$, Matsuia $\mathrm{Y}$, Takeuchib $\mathrm{H}$, Wildingc I, Connorc A, Abea $\mathrm{K}$, et al. Development of a gastric retentive system as a sustained-release formulation of pranlukast hydrate and its subsequent in vivo verification in human studies. Eur J Pharm Sci. 2014;53:62-8. 
8. Khosla R, Davis SS. The effect of polycarbophil on the gastric emptying of pellets. J Pharm Pharmacol. 1987;39:47-9.

9. Harris D, Fell JT, Sharma HL, Taylor DC. Gastrointestinal transit of potential bioadhesive formulations in man: a scintigraphic study. J Control Rel. 1990;12:45-53.

10. Säkkinnen M, Tuononen T, Jürjenson H, Veski $\mathrm{P}$, Marvola M. Evaluation of microcrystalline chitosans for gastro-retentive drug delivery. Eur J Pharm Sci. 2003;19:345-53.

11. Fix JA, Cargill R, Engle K. Controlled gastric emptying. III. Gastric residence time of a nondisintegrating geometric shape in human volunteers. Pharm Res. 1993;10:1087-9.

12. Klausner EA, Lavy E, Barta M, Cserepes E, Friedman M, Hoffman A. Novel gastroretentive dosage forms: evaluation of gastroretentivity and its effect on levodopa absorption in humans. Pharm Res. 2003;20:1466-73.

13. Ingani HM, Timmermans J, Moës A. Conception and in vivo investigation of peroral sustained release floating dosage forms with enhanced gastrointestinal transit. Int $\mathrm{J}$ Pharm. 1987;35:157-64.

14. Babu V, Khar R. In vitro and in vivo studies of sustained-release floating dosage forms containing salbutamol sulfate. Pharmazie. 1990;45(4):268-70.

15. Timmermans J, Moës A. How well do floating dosage forms float? Int J Pharm. 1990;62:20716.

16. Murata Y, Sasaki N, Miyamoto E, Kawashima $\mathrm{S}$. Use of floating alginate gel beads for stomach-specific drug delivery. Eur J Pharm Biopharm. 2000;50(2):221-6.

17. Hao S, Wang Y, Wang B, Zou Q, Zeng H, Chen $\mathrm{X}$, et al. A novel gastroretentive porous microparticle for anti-Helicobacter pyloritherapy: Preparation, in vitro and in vivo evaluation. Int J Pharm. 2014;463(1):10-21.

18. Moës A. Gastroretentive dosage forms. Crit Rev Ther Drug Carrier Syst. 1993;10(2):143-95.

19. Kikendall J, Friedman A, Oyewole M, Fleischer D, Johnson L. Pill-induced esophageal injury. Case reports and review of the medical literature. Dig Dis Sci. 1983;28:174-82.

20. Talukder R, Fassihi R. Gastroretentive delivery systems: a mini review. Drug Dev Ind Pharm. 2004;30(10):1019-28.

21. Rao K, Lakshmi K. Design, development and evaluation of clopidogrel bisulfate floating tablets. Int J Pharm Investig. 2014;4(1):19-26.

22. Shakyaa R, Thapaa P, Sahab RN. In vitro and in vivo evaluation of gastroretentive floating drug delivery system of ofloxacin Asian J Pharm Sci. 2013;8(3):191-8.

23. Ferrari P, Grossklauss D, Alvarez M, Paixão F, Andreis U, Crispim A, et al. A novel automated alternating current biosusceptometry method to characterization of controlled-release magnetic floating tablets of metronidazole. Drug Dev Ind Pharm. 2013;[Epub ahead of print].

24. Strübing $\mathrm{S}$, Abboud $\mathrm{T}$, Contri RV, Metz H, Mäder K. New insights on poly(vinyl acetate)based coated floating tablets: Characterisation of hydration and $\mathrm{CO} 2$ generation by benchtop MRI and its relation to drug release and floating strength. Eur J Pharm Biopharm. 2008;69(2):708-17.

25. Timmermans J, Moës A. Measuring the resultant-weight of an immersed test material: I. Validation of an apparatus and a method dedicated to pharmaceutical applications. Acta Pharm Technol. 1990;36:171-5.

26. Timmermans J, Moës A. Measuring the resultant-weigthof an immersed test material: II. Examples of kinetic determination applied to monolithic dosage forms. Acta Pharm Technol. 1990;36:176-80.

27. Timmermans J, Moës A. Apparatus and method for resultant-weight measuring system. US Patent 1991;5,076,107.

28. Strübing S, Metz H, Mäder K. Characterization of poly(vinyl acetate) based floating matrix tablets. J Control Rel. 2008;126(2):149-55.

29. Sauzet C, Claeys-Bruno M, Nicolas M, Kister J, Piccerelle P, Prinderre P. An innovative floating gastro retentive dosage system: Formulation and in vitro evaluation. Int $\mathrm{J}$ Pharm. 2009;378(12):23-9.

30. Baumgartner S, Kristl J, Vrecer F, Vodopivec P, Zorko B. Optimisation of floating matrix tablets and evaluation of their gastric residence time. Int J Pharm. 2000;195(1-2):125-35.

31. El-Gibaly I. Development and in vitro evaluation of novel floating chitosan microcapsules for oral use: comparison with non-floating chitosan microspheres. Int J Pharm. 2002;249(1-2):7-21.

32. Patel AR, Mahajan AN, Shah DA. Preparation and in vitro characterization of porous carrierbased floating microspheres of model drug for gastric delivery Der Pharmacia Lettre. 2011;3(3):432-42.

33. Kendre P, Chaudhari P. Formulation and Evaluation of Telmisartan Microspheres by Solvent Evaporation Technique. IAJPR. 2012;2(5):651-7.

34. Jain SK, Gupta A. Development of Gelucire 43/01 Beads of Metformin Hydrochloride for Floating Delivery. AAPS PharmSciTech. 2009;10(4):1128-36.

35. Shimpi S, Chauhan B, Mahadik K, Paradkar A. Preparation and evaluation of diltiazem hydrochloride-Gelucire 43/01 floating granules prepared by melt granulation. AAPS PharmSciTech. 2004;5(3):e43.

36. Yadav A, Jain DK. In vitro characterization of gastroretentive microballoons prepared by the emulsion solvent diffusion method. $\mathrm{J} \mathrm{Adv}$ Pharm Technol Res. 2010;1(1):56-67. 
37. Bulgarelli E, Forni F, Bernabei MT. Effect of matrix composition and process conditions on casein-gelatin beads floating properties. Int $\mathrm{J}$ Pharm. 2000;198(2):157-65.

38. Iannuccelli V, Coppi G, Sansone R, Ferolla G. Air compartment multiple-unit system for prolonged gastric residence. Part II. In vivo evaluation. Int J Pharm. 1998;174(1-2):55-62.

39. Ichikawa M, Kato T, Kawahara M, Watanabe S, Kayano M. A new multiple-unit oral floating dosage system. II: In vivo evaluation of floating and sustained-release characteristics with $\mathrm{p}$ aminobenzoic acid and isosorbide dinitrate as model drugs. J Pharm Sci. 1991;80(12):1153-6.

40. Meka L, Kesavan B, Kalamata V, Eaga C, Bandari S, Vobalaboina V, et al. Design and evaluation of polymeric coated minitablets as multiple unit gastroretentive floatingdrug delivery systems for furosemide. J Pharm Sci. 2009;98(6):2122-32.

41. Arza R, Gonugunta C, Veerareddy P. Formulation and evaluation of swellable and floating gastroretentive ciprofloxacin hydrochloride tablets. AAPS PharmSciTech. 2009;10(1):220-6.

42. Patel A, Modasiya M, Shah D, Patel V. Development and in vivo floating behavior of verapamil $\mathrm{HCl}$ intragastric floating tablets. AAPS PharmSciTech. 2009;10(1):310-5.

43. Bomma R, Naidu RS, Yamsani M, Veerabrahma K. Development and evaluation of gastroretentive norfloxacin floating tablets. Acta Pharm. 2009;59(2):211-21.

44. Rajinikanth P, Mishra B. Stomach-site specific drug delivery system of clarithromycin for eradication of Helicobacter pylori. Chem Pharm Bull (Tokyo). 2009;57(10):1068-75.

45. Tadros M. Controlled-release effervescent floating matrix tablets of ciprofloxacin hydrochloride: development, optimization and in vitro-in vivo evaluation in healthy human volunteers. Eur J Pharm Biopharm. 2010;74(2):332-9.

46. Zhang C, Xu M, Tao X, Tang J, Liu Z, Zhang $Y$, et al. A floating multiparticulate system for ofloxacin based on a multilayer structure: In vitro and in vivo evaluation. Int $\mathrm{J}$ Pharm. 2012;430(1-2):141-50.

47. Jagdale S, Kurhe P, Kuchekar B, Chabukswar A. Application of design of experiments to optimizing novel gastroretentive drug delivery of simvastatin. Curr Drug Deliv. 2013;10(5):527-41.

48. Malakar J, Datta PK, Purakayastha SD, Dey S, Nayak AK. Floating capsules containing alginate-based beads of salbutamol sulfate:In vitro-in vivo evaluations. Int J Biol Macromol. 2014;64:181-9.

49. Diao Y, Tu X. Development and pharmacokinetic study of miocamycin sustained-release tablet remaining--floating in stomach. Yao Xue Xue Bao. 1991;26(9):695700.

50. Oth M, Franz M, Timmermans J, Möes A. The bilayer floating capsule: a stomach-directed drug delivery system for misoprostol. Pharm Res. 1992;9(3):298-302.

51. Desai S, Bolton S. A floating controlled-release drug delivery system: in vitro-in vivo evaluation. Pharm Res. 1993;10(9):1321-5.

52. Whitehead L, Fell JT, Collett JH, Sharma HL, Smith A-M. Floating dosage forms: an in vivo study demonstrating prolonged gastric retention. J Control Rel. 1998;55(1):3-12.

53. Stops F, Fell JT, Collett JH, Martini LG, Sharma HL, Smith A-M. The use of citric acid to prolong the in vivo gastro-retention of a floatingdosage form in the fasted state. Int $\mathrm{J}$ Pharm. 2006;308(1-2):8-13.

54. Stops F, Fell JT, Collett JH, Martini LG, Sharma HL, Smith A-M. Citric acid prolongs the gastro-retention of a floating dosage form and increases bioavailability of riboflavin in the fasted state. Int J Pharm. 2006;308(1-2):14-24.

55. Badve SS, Sher P, Korde A, Pawar AP. Development of hollow/porous calcium pectinate beads for floating-pulsatile drug delivery Eur J Pharm Biopharm. 2007;65(1):8593.

56. Ali J, Arora S, Ahuja A, Babbar AK, Sharma RK, Khar RK, et al. Formulation and development of hydrodynamically balanced system for metformin: In vitro and in vivo evaluation. Eur J Pharm Biopharm. 2007;67(1):196-201.

57. Zou H, Jiang X, Kong L, Gao S. Design and gamma-scintigraphic evaluation of a floating and pulsatile drug delivery system based on an impermeable cylinder. Chem Pharm Bull (Tokyo). 2007;55(4):580-5.

58. Ali J, Arora S, Ahuja A, Babbar A, Sharma R, Khar R. Formulation and development of floating capsules of celecoxib: in vitro and in vivo evaluation. AAPS PharmSciTech. 2007;8(4):E119.

59. Yao H, Yao H, Zhu J, Yu J, Zhang L. Preparation and evaluation of a novel gastric floating alginate/poloxamer inner-porous beads using foam solution. Int J Pharm. 2012;422(12):211-9.

60. He S, Li F, Zhou D, Du J, Huang Y. Formulation and evaluation of novel coated floating tablets of bergenin and cetirizine dihydrochloride for gastric delivery. Drug Dev Ind Pharm. 2012;38(10):1280-8.

61. Jain SK, Agrawal GP, Jain NK. A novel calcium silicate based microspheres of repaglinide: In vivo investigations. $\mathrm{J}$ Control Rel. 2006;113(2):111-16.

62. Goole J, Gansbeke BV, Pilcer G, Deleuze P, Blocklet D, Goldman S, et al. Pharmacoscintigraphic and pharmacokinetic evaluation on healthy human volunteers of 
sustained-release floating minitablets containing levodopa and carbidopa. Int $\mathrm{J}$ Pharm. 2008;364(1):54-63.

63. Chavanpatil M, Jain P, Chaudhari S, Shear R, Vavia P. Development of sustained release gastroretentive drug delivery system for ofloxacin: in vitro and in vivo evaluation. Int $\mathrm{J}$ Pharm. 2005;304(1-2):178-84.

64. Mostafavi A, Emami J, Varshosaz J, Davies NM, Rezazadeh M. Development of a prolonged-release gastroretentive tablet formulation of ciprofloxacin hydrochloride: Pharmacokinetic characterization in healthy human volunteers. Int J Pharm. 2011;409(12):128-36.

65. Menon A, Ritschel W, Sakr A. Development and evaluation of a monolithic floating dosage form for furosemide. $\mathrm{J}$ Pharm Sci. 1994;83(2):239-45.

66. Hamdani J, Goole J, Moës A, Amighi K. In vitro and in vivo evaluation of floating riboflavin pellets developed using the melt pelletization process. Int J Pharm. 2006;323(12):86-92.

67. Mastiholimath V, Dandagi P, Gadad A, Mathews R, Kulkarni A. In vitro and in vivo evaluation of ranitidine hydrochloride ethyl cellulose floating microparticles. J Microencapsul. 2008;25(5):307-14.

68. Zhang Z, Peng B, Yang X, Wang C, Sun G, Pan W. Design and evaluation of a novel floating osmotic pump system. J Pharm Pharm Sci. 2009;12(1):129-37.

69. Abdelbary AA, Elsayed I, Elshafeey AH. Design and development of novel lipid based gastroretentive delivery system: response surface analysis, in-vivo imaging and pharmacokinetic study. Drug Deliv. 2013;[Epub ahead of print].

70. Guguloth M, Bomma R, Veerabrahma K. Development of sustained release floating drug delivery system for norfloxacin: in vitro and in vivo evaluation. PDA J Pharm Sci Technol. 2011;65(3):198-206.

71. Sawicki W. Pharmacokinetics of verapamil and norverapamil from controlled release floating pellets in humans. Eur $\mathrm{J}$ Pharm Biopharm. 2002;53(1):29-35.

72. Peterson WL. Helicobacter pylori and Peptic Ulcer Disease. N Engl J Med. 1991;324:1043-8.

73. Rajinikanth P, Balasubramaniam J, Mishra B. Development and evaluation of a novel floating in situ gelling system of amoxicillin for eradication of Helicobacter pylori. Int J Pharm. 2007;335(1-2):114-22.

74. Ishak RAH, Awad GAS, Mortada ND, Nour SAK. Preparation, in vitro and in vivo evaluation of stomach-specific metronidazoleloaded alginate beads as local anti-Helicobacter pyloritherapy. J Control Rel. 2007;119(2):20714.
75. Rajinikanth P, Mishra B. Floating in situ gelling system for stomach site-specific delivery of clarithromycin to eradicate H. pylori. J Control Rel. 2008;125(1):33-41.

76. Rajinikanth P, Mishra B. Preparation and in vitro characterization of gellan based floating beads of acetohydroxamic acid for eradication of H. pylori. Acta Pharm. 2007;57(4):413-27.

77. Shah S, Qaqish R, Patel V, Amiji M. Evaluation of the factors influencing stomach-specific delivery of antibacterial agents for Helicobacter pylori infection. J Pharm Pharmacol. 1999;51:667-72.

78. Yokel R, Dickey K, Goldberg A. Selective adherence of a sucralfate-tetracycline complex to gastric ulcers: Implications for the treatment of helicobacter pylori. Biopharm Drug Disposition. 1995;16:475-9.

79. Umamaheshwari R, Suman R, Jain N. Anti Helicobacter pylori effect of mucoadhesive nanoparticle bearing amoxicillin in experimental gerbils. APPS Pharm Sci Tech. 2004;5:60-8.

80. Jang SW, Lee JW, Park SH, Kim JH, Yoo M, $\mathrm{Na} \mathrm{DH}$, et al. Gastroretentive drug delivery system of DA-6034, a new flavonoid derivative, for the treatment of gastritis. Int $\mathrm{J}$ Pharm. 2008;356(1-2):88-94.

81. Jain A, Pandey V, Ganeshpurkar A, Dubey N, Bansal D. Formulation and characterization of floating microballoons of Nizatidine for effective treatment of gastric ulcers in murine model. Drug Deliv. 2014; [Epub ahead of print].

82. Nayak A, Jain S, Pandey R. Controlling release of metformin $\mathrm{HCl}$ through incorporation into stomach specific floating alginate beads. Mol Pharm. 2011;8(6):2273-81.

83. Ramachandran S, Shaheedha $S$, Thirumurugan G, Dhanaraju M. Floating controlled drug delivery system of famotidine loaded hollow microspheres (microballoons) in the stomach. Curr Drug Deliv. 2010;7(1):93-7.

84. Shishu, Gupta N, Aggarwal N. Stomach-specific drug delivery of 5-fluorouracil using floating alginate beads. AAPS PharmSciTech. 2007;8(2): Article 48.

85. Ichikawa M, Watanabe S, Miyake S. A new multiple-unit oral floating dosage system. I: preparation and in vitro evaluation of floating and sustained-release characteristics. J Pharm Sci. 1991;80:1062-6.

86. Goole J, Deleuze P, Vanderbist F, Amighi K. New levodopa sustained-release floating minitablets coated with insoluble acrylic polymer. Eur J Pharm Biopharm. 2008;68(2):310-18.

87. Goole J, Vanderbist F, Amighi K. Development and evaluation of new multiple-unit levodopa sustained-release floating dosage forms. Int $\mathrm{J}$ Pharm. 2007;334(1-2):35-41.

88. Nama M, Gonugunta C, Veerareddy PR. Formulation and evaluation of gastroretentive 
dosage forms of Clarithromycin. AAPS PharmSciTech. 2008;9(1):231-7.

89. Chaturvedi K, Umadevi S, Vaghani S. Floating matrix dosage form for propranolol hydrochloride based on gas formation technique: development and in vitro evaluation. Sci Pharm. 2010;78(4):927-39.

90. Desai SR, Rohera B. Formulation, in vitro evaluation and study of variables on tri-layered gastro-retentive deliverysystem of diltiazem HCl. Drug Dev Ind Pharm. 2014;40(3):380-9.

91. Choi BY, Park HJ, Hwang SJ, Park JB. Preparation of alginate beads for floating drug delivery system: effects of $\mathrm{CO} 2$ gas-forming agents. Int J Pharm. 2002;239(1-2):81-91.

92. Sriamornsak P, Sungthongjeen S, Puttipipatkhachorn S. Use of pectin as a carrier for intragastric floating drug delivery: Carbonate salt contained beads. Carbohydr Polym. 2007;67(3):436-45.

93. Asnaashari S, Khoei N, Zarrintan M, Adibkia K, Javadzadeh Y. Preparation and evaluation of novel metronidazole sustained release and floating matrix tablets. Pharm Dev Technol. 2011;16(4):400-7.

94. Patel D, Patel M, Patel A, Patel C. Formulation and evaluation of mixed matrix gastro-retentive drug delivery for famotidine. Int $\mathrm{J}$ Pharm Investig. 2011;1(4):247-54

95. Chen Y, Lee L, Ho H, Sha C, Sheu M. Evaluation of water uptake and mechanical properties of blended polymer films for preparing gas-generated multiple-unit floating drug delivery systems. J Pharm Sci. 2012;101(10):3811-22.

96. Sungthongjeen S, Sriamornsak P, Puttipipatkhachorn S. Design and evaluation of floating multi-layer coated tablets based on gas formation. Eur J Pharm Biopharm. 2008;69(1):255-63.

97. Jiménez-Martínez I, Quirino-Barreda T, Villafuerte-Robles L. Sustained delivery of captopril from floating matrix tablets. Int $\mathrm{J}$ Pharm. 2008;362(1-2):37-43.

98. Fukuda M, Peppas NA, McGinity JW. Floating hot-melt extruded tablets for gastroretentive controlled drugrelease system J Control Rel. 2006;115(2):121-9.

99. Davis SS, Stockwell AF, Taylor MJ, Hardy JG, Whalley DR, Wilson CG, et al. The effect of density on the gastric emptying of single and multiple-unit dosage forms. Pharm Res. 1986;3:208-13.

100. Dey S, Mazumder B, Chattopadhyay S, Das MK, Sinha S, Ganguly S, et al. Polymers derived from Xanthomonas campesteris and Cyamopsis tetragonolobus used as retardant materials for the formulation of sustained release floating matrix tablet of atenolol. Int $\mathrm{J}$ Biol Macromol. 2014;65:346-56.

101. Sheth P, Tossounian J. The hydrodynamically balanced system (HBSE): a novel drug delivery system for oral use. Drug Dev Ind Pharm. 1984;10:313-39.

102. Kumar MK, Shah MH, Ketkar A, Mahadik KR, Paradkar A. Effect of drug solubility and different excipients on floating behaviour and release from glyceryl monooleate matrices. Int J Pharm. 2004;272(1-2):151-60.

103. Malakar J, Nayak AK, Pal D. Development of cloxacillin loaded multiple-unit alginate-based floatingsystem by emulsion-gelation method. Int J Biol Macromol. 2012;50(1):138-47.

104. Sriamornsak P, Thirawong N, Puttipipatkhachorn S. Morphology and buoyancy of oil-entrapped calcium pectinate gel beads. AAPS J. 2004;6(3):e24.

105. Sriamornsak P, Thirawong N, Puttipipatkhachorn S. Emulsion gel beads of calcium pectinate capable of floating on the gastric fluid: effect of some additives, hardening agent or coating on release behavior of metronidazole. Eur J Pharm Sci. 2005;24(4):363-73

106. Eberle VA, Schoelkopf J, Gane PAC, Alles R, Huwyler J, Puchkov M. Floating gastroretentive drug delivery systems: Comparison of experimental and simulated dissolution profiles and floatation behavior. Eur J Pharm Sci. 2014;58:34-43.

107. Streubel A, Siepmann J, Bodmeier R. Floating matrix tablets based on low density foam powder: effects of formulation and processing parameters on drug release. Eur J Pharm Sci. 2003;18(1):37-45.

108. Streubel A, Siepmann J, Bodmeier R. Floating microparticles based on low density foam powder. Int J Pharm. 2002;241(2):279-92.

109. Sharma S, Pawar A. Low density multiparticulate system for pulsatile release of meloxicam. Int J Pharm. 2006;313(1-2):150-8.

110. Pandya N, Pandya M, Bhaskar VH. Preparation and in vitro Characterization of Porous CarrierBased GlipizideFloating Microspheres for Gastric Delivery. Journal of Young Pharmacists. 2011;3(2):97-104.

111. Jain SK, Awasthi AM, Jain NK, Agrawal GP. Calcium silicate based microspheres of repaglinide for gastroretentivefloating drug delivery: Preparation and in vitro characterization. J Control Rel. 2005;107(2):300-9.

112. Saravanan M, Anupama B. Development and evaluation of ethylcellulose floating microspheres loaded with ranitidine hydrochloride by novel solvent evaporationmatrix erosion method. Carbohydr Polym. 2011;85(3):592-8.

113. Li Z, Xu H, Li S, Li Q, Zhang W, Ye T, et al. A novel gastro-floating multiparticulate system for dipyridamole (DIP) based on a porous and lowdensity matrix core: In vitro and in vivoevaluation. Int J Pharm. 2014;461(1-2):5408. 
114. Sato Y, Kawashima Y, Takeuchi H, Yamamoto $H$. In vitro and in vivo evaluation of riboflavincontaining microballoons for afloating controlled drug delivery system in healthy humans. Int J Pharm. 2004;275(1-2):97-107.

115. Sato Y, Kawashima Y, Takeuchi H, Yamamoto $H$. Physicochemical properties to determine the buoyancy of hollow microspheres (microballoons) prepared by the emulsion solvent diffusion method. Eur J Pharm Biopharm. 2003;55(3):297-304.

116. Liu Y, Zhang J, Gao Y, Zhu J. Preparation and evaluation of glyceryl monooleate-coated hollow-bioadhesive microspheres for gastroretentive drug delivery. Int $\mathrm{J}$ Pharm. 2011;413(1-2):103-9.

117. Kawashima Y, Niwa T, Takeuchi H, Hino T, Ito Y. Preparation of multiple unit hollow microspheres (microballoons) with acrylic resin containing tranilast and their drug release characteristics (in vitro) and floating behavior (in vivo). J Control Rel. 1991;16(3):279-89.

118. El-Kamel AH, Sokar MS, Gamal SSA, Naggar VF. Preparation and evaluation of ketoprofen floating oral delivery system. Int $\mathrm{J}$ Pharm. 2001;220(1-2):13-21.

119. Thanoo BC, Sunny MC, Jayakrishnan A. Oral sustained-release delivery systems using polycarbonate microspheres capable of floating on the gastric fluid. J Pharm Pharmacol. 1993;45:21-4.

120. Joseph NJ, Lakshmi S, Jayakrishnan A. A floating-type oral dosage form for piroxicam based on hollow polycarbonate microspheres: in vitro and in vivo evaluation in rabbits. J Control Rel. 2002;79(1-3):71-9.

121. Whitehead L, Fell J, Collett J. Development of a gastroretentive dosage form. Eur J Pharm Sci. 1996;4(Suppl.):S182.

122. Arya P, Pathak K. Assessing the viability of microsponges as gastro retentive drug deliverysystem of curcumin: Optimization and pharmacokinetics. Int J Pharm. 2014;460(12):1-12.

123. Hao S, Wang Y, Wang B, Deng J, Zhu L, Cao Y. Formulation of porous poly(lactic-coglycolic acid) microparticles byelectrospray deposition method for controlled drug release. Materials Science and Engineering: C. 2014;39:113-9.

124. Oh T-O, Kim J-Y, Ha J-M, Chi S-C, Rhee Y-S, Park $\mathrm{C}-\mathrm{W}$, et al. Preparation of highly porous gastroretentive metformin tablets using a sublimation method. Eur J Pharm Biopharm. 2013;83(3):460-7.

125. Krögel I, Bodmeier R. Floating or pulsatile drug delivery systems based on coated effervescent cores. Int J Pharm. 1999;187(2):175-84.

126. Lingam $M$, Ashok $T$, Venkateswarlu V, Rao YM. Design and evaluation of a novel matrix type multiple units as biphasic gastroretentive drug delivery systems. AAPS PharmSciTech. 2008;9(4):1253-61.

127. Khan Z, Tripathi R, Mishra B. Floating elementary osmotic pump tablet (FEOPT) for controlled delivery of diethylcarbamazine citrate: a water-soluble drug. AAPS PharmSciTech. 2011;12(4):1312-23.

128. Acharya S, Patra S, Pani NR. Optimization of HPMC and carbopol concentrations in noneffervescent floating tablet through factorial design. Carbohydr Polym. 2014;102:360-8.

129. Bogentoft C. Oral controlled-release dosage forms in perspective. Pharm Int. 1982;3:366-9.

130. Singh L, Rajesh K, Umalkar D, Chauhan V, Rana V, Vasava K. Floating effervescent tablet: A review. J Pharm Biomed Sci. 2011;5:1-6.

131. Washington $\mathrm{N}$, Washington $\mathrm{C}$, Wilson CG, Davis SS. What is liquid gaviscon? A comparison of four international formulations. Int J Pharm. 1986;34:105-9.

132. Nathalie R, Jean-Christophe L, Ewart CT, Eric $\mathrm{D}$, Pierre B. Prevention of the sticking tendency of floating minitablets filled into hard gelatin capsules. Eur J Pharm Biopharm. 1997;43:16571.

133. Mouzam MI, Dehghan MHG, Asif S, Sahuji T, Chudiwal P. Preparation of a novel floating ring capsule-type dosage form for stomach specific delivery. Saudi Pharm J. 2011;19(2):85-93.

134. Tardieu A, Luzzata B. Polymorphism of lipid. A novel cubic phase - a cage-like network of rods with enclosed spherical micelles. Biochim Biophys Acta. 1970;219:11-7.

135. Dorożyński $\mathrm{P}$, Kulinowski $\mathrm{P}$, Mendyk A, Jachowicz R. Gastroretentive drug delivery systems with 1-dopa based on carrageenans and hydroxypropylmethylcellulose. Int $\mathrm{J}$ Pharm. 2011;404(1-2):169-75.

136. Mishra S, Pathak K. Formulation and evaluation of oil entrapped gastroretentive floating gel beads of loratadine. Acta Pharm. 2008;58(2):187-97.

137. Mishra S, Philip A, Pathak K. Passage-delaying microbeads for controlled delivery of loratadine. PDA J Pharm Sci Technol. 2008;62(6):421-8.

138. Adel S, Elkasabgy N. Design of innovated lipidbased floating beads loaded with an antispasmodic drug: in-vitro and in-vivo evaluation. J Liposome Res. 2013; [Epub ahead of print].

139. Chen R-N, Ho H-O, Yu C-Y, Sheu M-T. Development of swelling/floating gastroretentive drug delivery system based on a combination of hydroxyethyl cellulose and sodium carboxymethyl cellulose for Losartan and its clinical relevance in healthy volunteers with CYP2C9 polymorphism. Eur J Pharm Sci. 2010;39(1-3):82-9.

140. Jagdale S, Patil S, Kuchekar B. Application of design of experiment for floating drug delivery of tapentadol hydrochloride. Comput Math Methods Med. 2013;2013:625729. 
141. Hu L, Li L, Yang X, Liu W, Yang J, Jia Y, et al. Floating matrix dosage form for dextromethorphan hydrobromide based on gas forming technique: In vitro and in vivo evaluation in healthy volunteers. Eur J Pharm Sci. 2011;42(1-2):99-105.

142. Paula HCB, Oliveira EFd, Abreu FOMS, Paula RCMd. Alginate/cashew gum floating bead as a matrix for larvicide release. Mater Sci Eng, C. 2012;32(6):1421-7.

143. Tripathi G, Singh S. Formulation and In Vitro evaluation of $\mathrm{pH}$ sensitive oil entrapped polymeric blended gellan gum buoyant beads of clarithromycin. Daru. 2010;18(4):247-53.

144. Tripathi G, Singh S, Nath G. Formulation and In-vitro Evaluation of $\mathrm{pH}$-Sensitive Oil Entrapped Polymeric Blend AmoxicillinBeads for the Eradication of Helicobacter pylori. Iran J Pharm Res. 2012;11(2):447-55.

145. Kim J, Rhee Y, Park C, Ha J, Park E. Preparation and evaluation of dual-mode floating gastroretentive tablets containing itraconazole. Drug Deliv. 2013; [Epub ahead of print].
146. Prajapati VD, Jani GK, Khutliwala TA, Zala BS. Raft forming system-An upcoming approach of gastroretentive drug delivery system. J Control Rel. 2013;168:151-65.

147. Mohanlal DK, Bhalachandra DN, Vijay DV, inventors; US 7776345 B2, assignee. Gastric Retention Controlled Drug Delivery System 2010.

148. Spickett RGW, Vidal JLF, Escoi JC, inventors; US5288506 A, assignee. Antacid compositions with prolonged gastric residence time. USA1994.

149. Franz MR, Oth MP, inventors; US5232704 A, assignee. Sustained release, bilayer buoyant dosage form. USA1993.

150. Gusler G, Berner B, Chau M, Padua A, inventors; US6723340 B2, assignee. Optimal polymer mixtures for gastric retentive tablets. USA2004.

151. No-authors-listed. Gabapentin ExtendedRelease - Depomed: Gabapentin ER, Gabapentin Gastric Retention, Gabapentin GR. Drugs R D. 2007;8(5):317-20. 
Table 1: Parameters affecting the floating behavior of FDDS based on the type of buoyancy-generating agents.

\begin{tabular}{|c|c|c|c|}
\hline Category of Buoyancy-generating agents & Factors influencing buoyancy & Comments & References \\
\hline \multirow{6}{*}{ Gas-generating agents } & The amount of gas-generating agent & $\uparrow$ Amount $\rightarrow \downarrow$ FLT $\rightarrow \uparrow$ GRT & $\begin{array}{c}(44,45,76,84,86- \\
89)\end{array}$ \\
\hline & $\begin{array}{l}\text { The type of carbonate salts e.g. } \mathrm{NaHCO}_{3} \text {, } \\
\mathrm{Na}_{2} \mathrm{CO}_{3}, \mathrm{CaCO}_{3}, \mathrm{~K}_{2} \mathrm{CO}_{3}\end{array}$ & $\begin{array}{l}\mathrm{CaCO}_{3} \text { and } \mathrm{NaHCO}_{3} \text { are better in terms of FLT } \\
\text { compared to other salts with the superiority of } \\
\text { CaCO3 in enhanced floatation and bead surface } \\
\text { smoothness }\end{array}$ & $(91,92)$ \\
\hline & The type of polymer or diluent & $\begin{array}{l}\text { Psyllium }>\text { HPMC E5>Carbopol } \\
\text { Xanthan Gum>HPMC K4M or HPMC K15M }\end{array}$ & $\begin{array}{l}(21,93,94) \\
(92)\end{array}$ \\
\hline & The coating type and concentration & $\begin{array}{l}\text { Soluble polymers as HPMC, PEG 6000, PEG } \\
600 \text {, and Kollicoat } \AA \text { IR increased water uptake } \\
\text { ability of insoluble polymers (Eudragit } \AA \text { NE, } \\
\text { RS, and RL; Surelease } \AA \text {; and Kollicoat } \AA \text { SR) } \\
\rightarrow \downarrow \text { FLT } \\
\uparrow \text { coating conc. } \rightarrow \uparrow F L T\end{array}$ & $(28,95,96)$ \\
\hline & The compression pressure & $\uparrow$ compression force $\rightarrow \uparrow \mathrm{FLT}$ & $(97)$ \\
\hline & The preparation method & $\begin{array}{l}\text { hot-melt extrusion }(\mathrm{HME})>\text { direct-compression } \\
\text { Freeze-drying }>\text { air-drying }\end{array}$ & $\begin{array}{l}(92,98) \\
(96) \\
\end{array}$ \\
\hline \multirow{4}{*}{ Air-entrapping swellable polymers } & \multirow{3}{*}{ The polymer type } & $\begin{array}{l}\text { Blends of alginate and HPMC, alginate and } \\
\text { chitosan, carrageenans and HPMC, xanthan } \\
\text { gum and guar gum. }\end{array}$ & $(16,99-101)$ \\
\hline & & Glyceryl monooleate (GMO) & $(102)$ \\
\hline & & $\begin{array}{l}\text { PEO WSR 60K, PEO WSR } 303 \text { and HPMC K4 } \\
\text { M }\end{array}$ & $(56)$ \\
\hline & The drug or excipients type & $\begin{array}{l}\uparrow \text { polar drug or } \downarrow \text { non-polar drug amount } \rightarrow \uparrow \\
\text { water uptake } \rightarrow \downarrow \text { FLT } \\
\uparrow \text { stearic acid or PEG amount } \rightarrow \downarrow \text { water uptake } \\
\text { or } \uparrow \text { viscosity } \rightarrow \uparrow \text { FLT } \\
\text { Mw of PEG did not significantly affect FLT }\end{array}$ & $(102)$ \\
\hline
\end{tabular}




\begin{tabular}{|c|c|c|c|}
\hline \multirow{4}{*}{ Inherent low density agents } & \multirow{4}{*}{$\begin{array}{l}\text { The type and concentration of low } \\
\text { density excipient }\end{array}$} & $\begin{array}{l}\text { Oils (light mineral, olive, sunflower, peppermint, } \\
\text { sesame, rice, soybean and corn oil) }(10-30 \%)\end{array}$ & $(16,103-105)$ \\
\hline & & Magnesium stearate $(5 \%)$ & $(74)$ \\
\hline & & Silicon dioxide (Aerosil R972) & $(29)$ \\
\hline & & Functionalized $\mathrm{CaCO}_{3}$ & $(106)$ \\
\hline \multirow{4}{*}{ Highly porous excipients or Pore formers } & \multirow{4}{*}{$\begin{array}{l}\text { The type of porous or pore forming } \\
\text { agents }\end{array}$} & Casein & $(37)$ \\
\hline & & Polypropylene foam powder (Accurel®) & $(107,108)$ \\
\hline & & PEG & $(112)$ \\
\hline & & Mannitol & $(113)$ \\
\hline \multirow{6}{*}{$\begin{array}{l}\text { Hollow/porous particles induced by } \\
\text { preparation methods }\end{array}$} & \multirow{6}{*}{ The method of preparation applied } & Emulsion-solvent diffusion method & $(114-118)$ \\
\hline & & Ionotropic gelation method & $(31)$ \\
\hline & & Solvent evaporation method & $(119,120)$ \\
\hline & & Freeze-drying method & $(52,121)$ \\
\hline & & Foam solution-based method & $(59)$ \\
\hline & & Electrospray method & $(17,123)$ \\
\hline Sublimation material & $\begin{array}{l}\text { The concentration of sublimating } \\
\text { substance }\end{array}$ & $\begin{array}{l}\uparrow \text { amount of camphor in tablet matrix } \rightarrow \downarrow \text { tablet } \\
\text { crushing strength after sublimation }\end{array}$ & $(124)$ \\
\hline
\end{tabular}

